\title{
European column buckling curves and finite element modelling including high strength steels
}

Jönsson, Jeppe; Stan, Tudor-Cristian

Published in:

Journal of Constructional Steel Research

Link to article, DOI:

10.1016/j.jcsr.2016.08.013

Publication date:

2017

Document Version

Peer reviewed version

Link back to DTU Orbit

Citation (APA):

Jönsson, J., \& Stan, T-C. (2017). European column buckling curves and finite element modelling including high strength steels. Journal of Constructional Steel Research, 128, 136-151.

https://doi.org/10.1016/j.jcsr.2016.08.013

\section{General rights}

Copyright and moral rights for the publications made accessible in the public portal are retained by the authors and/or other copyright owners and it is a condition of accessing publications that users recognise and abide by the legal requirements associated with these rights.

- Users may download and print one copy of any publication from the public portal for the purpose of private study or research.

- You may not further distribute the material or use it for any profit-making activity or commercial gain

- You may freely distribute the URL identifying the publication in the public portal

If you believe that this document breaches copyright please contact us providing details, and we will remove access to the work immediately and investigate your claim. 


\title{
European column buckling curves and finite element modelling including high strength steels
}

\author{
Jeppe Jönsson, Tudor-Cristian Stan \\ Technical University of Denmark, DTU Civil Engineering, Brovej Building 118, \\ DK-2800 Kgs. Lyngby
}

\begin{abstract}
Eurocode allows for finite element modelling of plated steel structures, however the information in the code on how to perform the analysis or what assumptions to make is quite sparse. The present paper investigates the deterministic modelling of flexural column buckling using plane shell elements in advanced non-linear finite element analysis (GMNIA) with the goal of being able to reestablish the European buckling curves. A short comprehensive historical review is given on the development of the European buckling curves and the related assumptions made with respect to deterministic modelling of column buckling. The European buckling curves allowing deterministic analytical engineering analysis of members are based on large experimental and parametric measurement programs as well as analytical, numerical and probabilistic investigations. It is of enormous practical value that modern numerical deterministic analysis can be performed based on given magnitudes of characteristic yield stress, material stressstrain relationship, and given characteristic values for imperfections and residual stresses. The magnitude of imperfections and residual stresses are discussed as well as how the use of equivalent imperfections may be very conservative if considered by finite element analysis as described in the current Eurocode code. A suggestion is given for a slightly modified imperfection formula within the Ayrton-Perry formulation leading to adequate inclusion of modern high grade steels within the original four bucking curves. It is also suggested that finite element or frame analysis may be performed with equivalent column bow imperfections extracted directly from the Ayrton-Perry formulation.
\end{abstract}

Keywords: Columns, Steel, Buckling curves, Eurocode, Stability, Imperfections, Residual stress, FE modelling, GMNIA.

\section{Introduction}

The European column buckling curves are based on extensive experimental research programs as well as theoretical, numerical and probabilistic investigations performed around the 1960's and early 1970's. Standardized buckling tests were performed at different laboratories and the gathered parametric information and results were analysed using both probabilistic and deterministic methods. The original experimental and theoretical (deterministic) basis for European buckling curves is respectively given by Sfinitesco [1] and Beer \& Schulz [2]. An early proposal of a series of buckling curves based on a probabilistic approach was given by Bjorhovde [3]. Strating \& Vos [4] demonstrated that buckling curves corresponding to a constant probability of failure can be determined from the distribution functions of the physical and geometric column parameters. This work was based on statistical information from the European test series on IPE160 sections, a theoretical nonlinear member theory and Monte Carlo simulation. They found a reasonable agreement with the experimental buckling curve (with the same confidence value). Strating \& Vos [4] found that for a column with the length $L$ the mean value $m$ of the bow imperfection corresponded well to $m=0.00085 L=L / 1176$

Email address: jej@byg.dtu.dk (Jeppe Jönsson) and that the mean plus 2 times the st. dev. $s$, corresponded to $m+2 s=0.00125 L=L / 800$. Bjorhovde [3] used a randomly distributed bow imperfection between $L / 1000$ and $L / 10000$ corresponding to the limits of the 95 percent confidence interval for the distribution of the bow imperfection with a mean value of $L / 1470$.

In 1975 Dwight [5] reports on the work towards incorporating the "Ayrton-Perry" approach including equivalent imperfections and a plateau corresponding to relative slenderness values lower than $\lambda_{0}=0.2$. The main results of the work of the European Convention for Constructional Steelwork (ECCS) was gathered in 1976 in the ECCS "Manual on Stability of Steel Structures" [6], which is a very thorough gathering of the academic state of the art of the European stability research at that time including references to many known related works. The resulting ECCS recommendations [7] came two years later. However, the five ECCS column buckling curves $\left(a_{o}, a, b, c, d\right)$ were just tabulated and the related analytical formulations were not given in either of these references. This was due to the fact that the "Ayrton-Perry" type approach [8] in the form proposed by Robertson [9] (the so-called "Perry-Robertson" formula) was not fully developed with respect to equivalent imperfections for these curves. Investigations performed in 1978 by Maquoi \& Rondal [10] with 7 proposals for the formulation of the equivalent imperfections made it possible to decide on 
an "Ayrton-Perry" approach. In the 1984 report on Eurocode 3 by Dowling et al [11] the "Ayrton-Perry" approach was included for simple member verification as well as the possibility of numerical verification using 1/1000 of the buckling length, $L$, as initial bow imperfection with simplified linear residual stress distributions. Furthermore, an equivalent geometric imperfection dependent on the buckling curve of the cross-section could be used. The simplified residual stress distributions including tubes were also given in the ECCS report on sway frames [12]. In the 1992 draft for development of Eurocode 3 [13] the Ayrton-Perry approach was included with a somewhat cumbersome awkward mix of definitions of the equivalent imperfections dependent on safety factors and on whether strong or weak axis was being analysed. In the case of strong axis buckling the equivalent imperfection was more or less extracted directly from the "Ayrton-Perry" based buckling curve. In case of weak axis buckling an equivalent imperfection was given as a fraction of the buckling length, but including a correction factor removing the (correct) influence of the yield stress. In this preliminary Eurocode 3 the previous proposal of allowing the use of assessment with residual stress and related bow imperfection was not included.

From 1992 until 2005 when the (EC3) Eurocode 3 part 1-1 [14] finally became a harmonized European standard the buckling curve formulation remained nearly unchanged. In this period the major research was related to the stability treatment of beam-columns with combined compression and bending as thoroughly described in the ECCS publication [15] giving the background documentation and design guidelines. Thus the formulation of the buckling curves in the harmonized European standard Eurocode 3 part 1-1 is based on the "Ayrton-Perry" formulation of the five buckling curves and alternatively numerical treatments can be performed using a set of very conservative equivalent imperfections. However, Eurocode 3 part 1-5 [16] includes an Annex $\mathrm{C}$ on FE-methods which in a relatively vague formulation allows a more refined analysis of the geometric imperfections and residual stress that respectively may correspond to $80 \%$ of the geometric "plate" fabrication tolerance and a residual stress pattern using mean amplitude values. Since the reference is to "plate" tolerances, it does indeed seem to be the intention that the over conservative equivalent bow imperfections from part 1-1 are to be used. This does not correspond to a more refined analysis as shown later in this paper, it is simply too conservative. The commentary to part 1-5 prepared by Johansson et al [17] gives recommendations on imperfections and residual stress, but does not shed light on the magnitude of the column bow imperfection. The ECCS document from 2006 [15] on the beam-column instability formulas in Eurocode 3 part 1-1 gives background documentation and references to papers in which numerical analysis has been used for verifying and evaluating the constants of the beamcolumn formulas. In these papers, found on the companion $\mathrm{CD}$, the residual stress distributions have mainly been the simplified distributions described in [11] and [12], but different parabolic distributions (with residual stresses in the same order of magnitude) have also been used and results have been compared. The conclusion is that use of the simplified linearized residual stress distributions lead to similar results, which seem to be a bit more conservative compared to the parabolic distribution. A mean value for the residual stress magnitude should be used and this is often for I-sections set to $30 \%$ or $50 \%$ of the yield stress (for S235 steel) dependent on the height to width ratio. However, it is also stated, discussed and shown that the magnitude of the residual stress is independent of the steel grade, see the work of Alpsten [18] and the ECCS manual on stability [6] especially the section concerning compression members of high strength steel. Residual stress magnitudes and distributions have been measured in numerous applications and in a multitude of specimens, mainly during the 1970 (many included in the works of Alpsten). However, with the increasing strengths of high strength steel and their introduction on the market there is a need for residual stress measurements concerning these "new" grades of steel. Recent experimental studies [19] confirm that for welded members this is also the case for high-strength steels. Naturally, if the magnitude of residual stresses is wrongly assumed to be proportional to the yield stress, the column buckling capacity of steel members found by finite element simulation will be underestimated for higher grades of steel. Moreover, since most numerical simulations regarding both flexural and lateral torsional buckling which include residual stresses are performed on grade S235 steel, the fact or statement that the maximum residual compressive stress is defined as a percentage of the yield stress might be misleading and may represent one of the reasons why conflicting assumptions can be found throughout the literature regarding this issue. This was pointed out in a recent paper by Boissonnade, [20], where this topic was studied for the case of lateral torsional buckling. Placing different steel grades on the same buckling curve leads to an overly conservative design for higher strength steels was pointed out by Dwight, [5], even before the establishment of the first tabulated buckling curves. While it is true that Eurocode 3 prescribes higher buckling curves for S460, all other steel grades fall into the same buckling curve.

Variations in the cross-section geometry are not taken into account, since it is assumed that the influence is minimal and thus nominal or mean values are used for the geometric parameters. Therefore deterministic column analysis is to be performed using a characteristic value for the yield stress, corresponding to a 95\% confidence level and all other parameters are taken as mean values. However, when introducing phenomena such as local imperfections and local buckling into the analysis, which is necessary for class 4 (slender) cross-sections, this may have to be reconsidered or calibrated by prescribing adequate levels of combined imperfections for example through the use of a square root of squares combination rule.

When it comes to finite element modelling of columns using shell elements, there are mainly two methods of analysis following the statements in the code and the development history. The first method (I) is to introduce mean bow-imperfections and adequate simplified mean residual stress distributions. The other method (II) is to introduce equivalent bow-imperfections that include all relevant effects. Of course within each of these methods there are a number of important choices, which have a great influence on the results. 
In this paper results and comparisons are expected to be generic in character. The finite element analysis and analytical computations have therefore been limited to standard hot rolled profiles IPE160, and HEB300, which are not prone to local buckling. Thus class 4 sections are not discussed in this work. Furthermore, the computations have been limited to strong axis buckling. The investigations performed have also included IPE500 and HEB500, but it has been deemed to be unnecessary to include all these very similar results. However, in section 6 results are included for the IPE500 in order to show that the benefits of the proposal made in this paper also apply for the IPE500 profile with a higher web slenderness.

In the following section the theoretical background for the Ayrton-Perry formulation of Eurocode 3 is briefly described and the theoretical imperfection formulation is clarified, so that the theoretical influence of the steel grade becomes clear.

Then in the next section the finite element modelling and boundary conditions are introduced, including subsections with discussions and brief descriptions on how the modelling of the steel material, the imperfections and the residual stress is performed.

With the finite element modelling in place the following section turn to the results and comparisons using method (I) with geometric bow imperfection and residual stress. The influence of residual stress distribution (linear or parabolic), the residual stress magnitude, the material stress-strain curve and the steel grade (yield stress) is investigated and discussed.

Then results and comparisons when using method (II) with equivalent imperfections are discussed and analysed. Two different magnitudes of the equivalent imperfections are investigated: 1) The equivalent imperfections taken as a fraction of the column length as stated in Eurocode 3 and the logical alternative 2) the equivalent imperfections are extracted directly from the analytical formulated Ayrton-Perry buckling curves. Also the influence of the choice of steel grade is illustrated.

Issues pointed out in this paper regarding the use of equivalent geometrical imperfections as well as the influence of the steel grade (yield stress magnitude) are discussed and a slightly modified imperfection formulation is suggested for consideration.

\section{Theoretical background}

The analytic Ayrton-Perry type approach yields the column reduction factor $\chi$ the so-called buckling curve expressed by the relative slenderness $\lambda$, the excentrictity $e$ and the kernel radius $k$ as follows:

$$
\chi=\frac{1}{\phi+\sqrt{\phi^{2}-\lambda^{2}}} \quad \text { where } \quad \phi=\frac{1}{2}\left(\lambda^{2}+\frac{e}{k}+1\right)
$$

The relative slenderness is a normalized slenderness, which can expressed by the yield stress $f_{y}$ and the elastic critical stress $\sigma_{c r}$ of the column as follows

$$
\lambda=\sqrt{\frac{f_{y}}{\sigma_{c r}}} \text { where } \quad \sigma_{c r}=\frac{\pi^{2} E i^{2}}{L^{2}}
$$

in which we have introduced Youngs elasticity modulus $E$ and the radius of inertia as $i=\sqrt{I / A}$ where $A$ is the cross-section area and $I$ is the appropriate second moment of area corresponding to the axis of bending. The introduced kernel radius is given as $k=W / A$, where $W$ is the appropriate section modulus.

Inserting the critical stress in the relative slenderness expression we may find an alternative expression for the column (buckling) length as follows:

$$
\lambda=\frac{L}{\pi i} \sqrt{\frac{f_{y}}{E}} \Leftrightarrow L=\pi i \sqrt{\frac{E}{f_{y}}} \lambda
$$

Historically, imperfections have been expressed as equivalent eccentricities $e$ given as a fraction of the column length, e.g. $L / \xi$ where the bow imperfection corresponds to a denominator of $\xi=1000$ and if residual stresses are included as equivalent imperfections the denominator value could be $\xi=250$ as conservatively recommended in the Eurocode 3 for buckling curve $a$ when using plastic cross-section properties. Following this practice for equivalent eccentricities given as a fraction of the buckling length, the normalized eccentricity can be expressed as:

$$
\frac{e}{k}=\frac{L / \xi}{k}=\frac{\pi i}{\xi k} \sqrt{\frac{E}{f_{y}}} \lambda=\alpha \varepsilon \lambda
$$

In which we have introduced the imperfection parameter $\alpha$ and the material parameter $\varepsilon$ as

$$
\alpha=\frac{\pi}{\xi} \frac{i}{k} \sqrt{\frac{E}{235 \mathrm{MPa}}} \quad \text { and } \quad \varepsilon=\sqrt{\frac{235 \mathrm{MPa}}{f_{y}}}
$$

Note that this theoretical imperfection parameter $\alpha$ is only dependent on cross-section properties and the chosen magnitude of imperfection through the magnitude of the denominator $\xi$. This is consistent with the current imperfection parameter in Eurocode for the S235 steel grade. The normalized eccentricity derived here is strictly theoretically derived and shows that if the bow imperfection and other imperfections are proportional to the length then equation (4) is the theoretical format. The imperfection parameter $\alpha$ introduced here is equivalent to the imperfection factor introduced in Eurocode, but independent of the steel yield stress, however the "artificial" plateau for low slenderness has not been introduced. This shows that it might be relevant to introduce the yield stress dependency of the buckling curves, meaning that there would have to be a set of curves for each grade of steel, however only one unique imperfection parameter would be needed and it would only relate to the cross-section shape and the bending axis in the same fashion as in the current Euocode 3 [14]. In the current code the normalized equivalent imperfection eccentricity for analytical member calculation is not given by equation (4) but by the following equation:

$$
\frac{e}{k}=\alpha(\lambda-0.2)
$$

In which the imperfection factor $\alpha$ takes a value dependent on which buckling curve is to be used. This formulation leads to 
the plateau and the requirement that the column reduction factor should be less than one. The equivalent imperfection built into the buckling curve is thus given by this equation (6) and can be calculated before any numerical calculation, this would be a natural choice, however as we shall see numerical simulations will lead to deviating curves dependent on the steel grade, since the parameter $\varepsilon$ has been omitted in the Eurocode definition of the imperfection as in equation (6).

\section{Finite element modelling assumptions}

The commercial software program ABAQUS [21] has been used for the finite element analysis presented in this paper. The simply supported columns are modelled using the generalpurpose S4 shell element (with full integration). This element has 4 corner nodes with 6 degrees of freedom each. The shell element is applicable for analysis involving finite membrane strains and large rotations. The columns considered in this paper are initially prismatic and have I-shaped cross-sections. Figure 1 shows the straight column superimposed with the strong axis buckling mode, which is mainly considered in this paper. The finite element model is meshed using 16 elements along the flange width, 16 elements along the web height and 200 elements along the beam length as illustrated in the upper left hand side of Figure 2.

The $x$-axis corresponds to the longitudinal beam axis and the $y$ - and $z$-axes are in the plane of the cross-section. The $y$-axis is parallel to the web and the $z$-axis is parallel to the flanges. The origin of the $(y, z)$ axes is situated at the elastic centre of the cross-section. The nodal displacements are referred to as the displacements $\left(U_{x}, U_{y}, U_{z}\right)$ and the rotations $\left(R_{x}, R_{y}, R_{z}\right)$ respectively in and about the global coordinate directions $(x, y, z)$, see Figure 2.

The end support conditions are modelled using kinematic coupling constraints. The $U_{x}$ and $U_{y}$ displacements of the end nodes of the flanges are coupled to the chosen master node displacements $U_{x}$ and $U_{y}$ at the web-flange intersections. This then allows us to couple the displacements $U_{x}, U_{z}$ and $R_{x}$ of all the web end nodes (including the web-flange intersection nodes) to the corresponding displacements at the chosen master node at

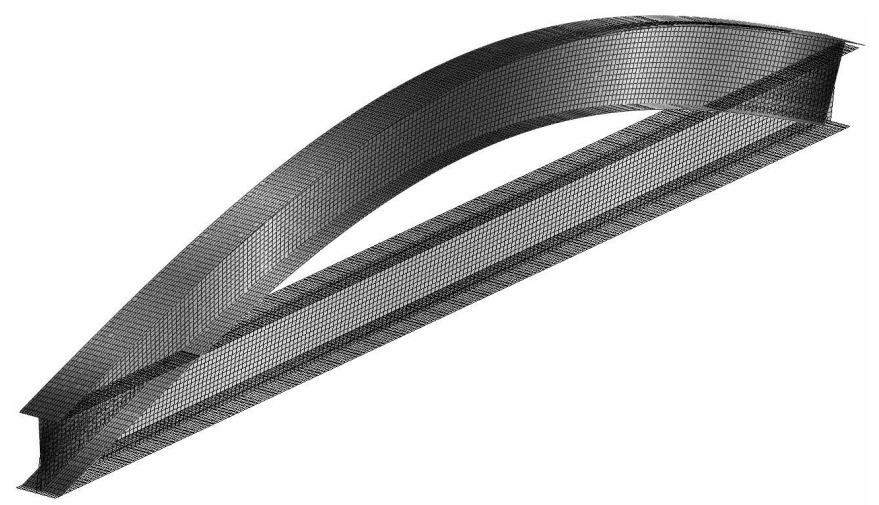

Figure 1: Illustration of the FE model in un-deformed and buckled state for strong axis column buckling.
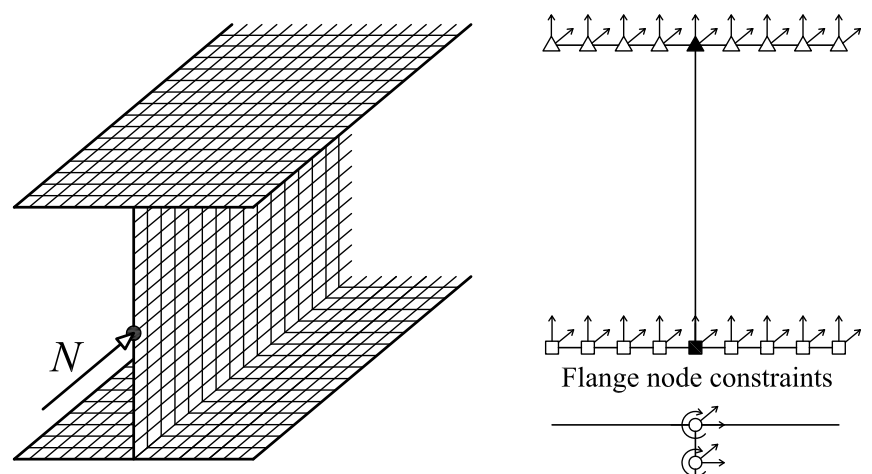

Flange node constraints
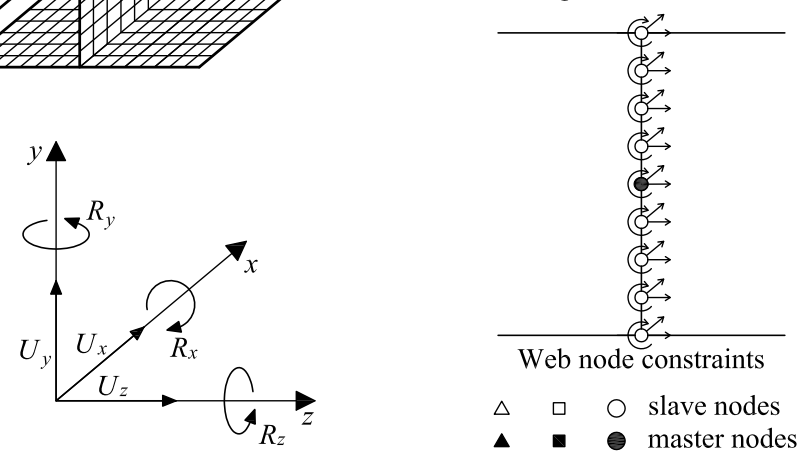

Figure 2: FE mesh and constrained degrees of freedom with the respective slave and master nodes.

the centre of the web. Thereby end boundary conditions used in this paper are only needed on the master node at the centroid of the web at each end of the member, see Figure 2.

With these constraints the end sections of the flanges and the web are allowed to "expand", but the nodes of the flanges and web are constrained to remain on a straight line. This also allows free warping of the end sections.

The end boundary conditions of both ends of the column with the described kinematic constraints are given as $U_{y}=U_{z}=$ $R_{x}=0$ at the central web node. The longitudinal displacement of the central web node at the middle of the member was also constrained to $U_{x}=0$ to keep the central position in space. Finally when investigating major axis buckling the transverse displacements out of the buckling plane are suppressed to $U_{z}=$ 0 along the length of the member at the web-flange intersection nodes. Thus column compression loading was applied at both ends as point loads acting at the central web node as shown in Figure 2.

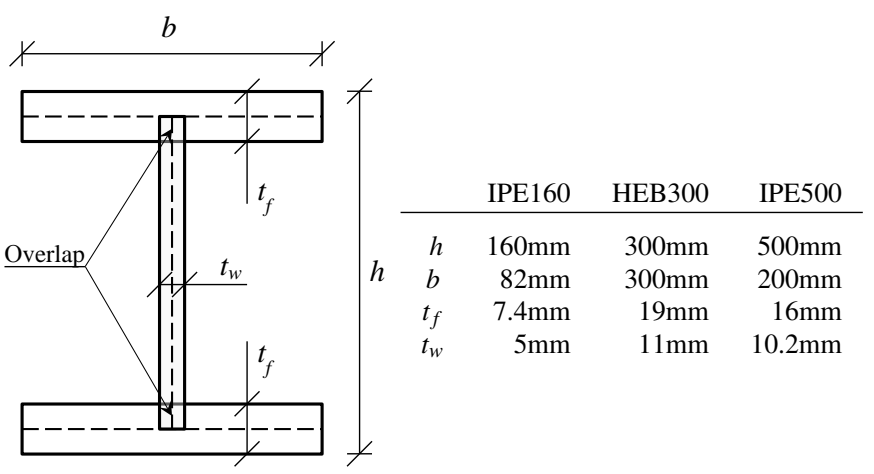

Figure 3: Cross-section dimensions used for midline shell modelling. 


\begin{tabular}{ccccc} 
& $\begin{array}{c}A \\
{\left[10^{3} \mathrm{~mm}^{2}\right]}\end{array}$ & $\begin{array}{c}W_{e l, y} \\
{\left[10^{3} \mathrm{~mm}^{2}\right]}\end{array}$ & $\begin{array}{c}W_{p l, y} \\
{\left[10^{3} \mathrm{~mm}^{2}\right]}\end{array}$ & $\begin{array}{c}I_{y} \\
{\left[10^{6} \mathrm{~mm}^{4}\right]}\end{array}$ \\
\hline IPE160 & 1.98 & 107 & 121.8 & 8.56 \\
HEB300 & 14.5 & 1640 & 1820 & 246 \\
IPE500 & 11.34 & 1886 & 2146 & 471
\end{tabular}

Table 1: Approximate cross-section properties used in analytical calculations.

The fillet present in hot rolled I-sections was not modelled and the shell elements have been modeled as midline elements, leading to a small material overlap at the flange and web joint lines. The modelled geometry is shown in Figure 3. However, the influence of the fillet was found to be negligible for lateral torsional buckling, see [22]. The cross-section properties (second moment of area, plastic modulus,etc.) used in the analytical formulations are calculated based on the geometry shown in Figure 3 including the small material overlap. The used crosssection properties are tabulated in Table 1.

The failure criterion used for the numerical simulations presented in this paper is the one recommended in Eurocode 3 part 1-5, [16], for structures susceptible to buckling, i.e. as the point at which the maximum load is attained. Thus the present analysis has been performed using the Static Riks (arc length method) algorithm.

\subsection{Material model}

In the finite element modelling of columns with plane shell elements there are several important factors to consider and to be aware of in order to obtain results in agreement with the code and the related probabilistic approach. The use of the characteristic yield stress related to the grade of steel and the shape of the material stress-strain curve is very important. The material stress-strain curve of structural steels is assumed to have a proportionality limit equal to the yield stress. Steels or metals with a lower proportionality limit and a significant initial material non-linearity will exhibit a much lower buckling load and the formulations in the Eurocode 3 are not applicable to these materials without modification. The yield plateau and strain hardening has an influence on short columns and beam-columns with low slenderness. The elastic modulus, $E$, (i.e. the inclination of the stress-strain curve), is also an important parameter, which corresponds to a mean value that in Eurocode 3 is always set to be $210 \mathrm{GPa}$. This is due to the fact that material tension tests are rather inaccurate and (bending) tests for determination of the elastic modulus of steel are not standardized.

Later in this paper, a number of steel grades and material models for finite element analyses are investigated. Annex $\mathrm{C}$ of Eurocode 3 part 1-5 [16] recommends the use of one of the following four material behavior models when performing plated finite element analysis:

a) elastic-plastic without strain hardening

b) elastic-plastic with a nominal plateau slope of $1 \mathrm{MPa}$

c) elastic-plastic with a strain hardening slope of $E / 100$

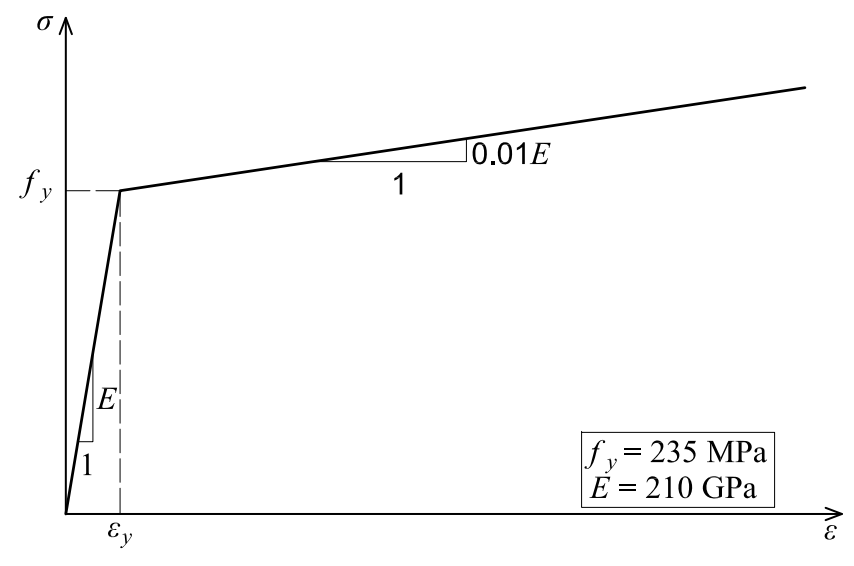

Figure 4: Bi-linear material curve with a yield stress of $f_{y}=235 \mathrm{MPa}$ and a hardening slope of $E / 100$ as used for the primary investigations of this paper.

\section{d) true stress-strain curve modified from test results}

An adequate material model should be chosen depending on the accuracy and the allowable strain required by the analysis. In buckling analysis there could be some dependency on the hardening behaviour, since the spreading of the plastic zone at the point of maximum bending could be of some importance in relation to the determination of the maximum load obtained from the non-linear analysis. However, the strains at the point of maximum loads are often limited in magnitude allowing a simple material model without considering the difference between true stresses - true strains and the engineering stress-strains. In order not to have convergence problems the bi-linear model c) with hardening slope of $E / 100$ has been chosen for the primary analysis examples of this paper. The yield stress used in the simulations of this paper, except when otherwise stated, is chosen as $f_{y}=235 \mathrm{MPa}$ as shown in the typical stress-strain curve in Figure 4. This choice of hardening slope also has a magnitude which is reasonable in relation to the magnitude of the initial hardening slope in structural steels after the plateau.

\subsection{Geometric imperfection}

The current European technical requirements for the execution of steel structures are specified in EN1090-2 [23]. These requirements include maximum levels for the fabrication tolerances such as bow imperfections and local imperfections. The maximum allowed bow imperfection is currently $L / 750$. The reason for this is briefly presented in the consistency report on equivalent geometric imperfections [24]. The characteristic value of the bow imperfection used in most investigations correspond to a mean imperfection of $L / 1000$, which in turn corresponds to $75 \%$ of the recommended tolerance value of $L / 750$ for steel columns. The investigation of Stating \& Vos [4] as mentioned in the introduction also confirms that this is a reasonable mean value for the bow imperfection. For critical plate buckling modes Eurocode 3 part 1-5 recommends the use of an imperfection magnitude of $80 \%$ of the geometric fabrication tolerance. However, this is intended for local buckling patterns and mean local imperfection magnitudes. The first set of European buckling curves were derived using deterministic 
numerical analysis based on the assumption of a global bow imperfection of $L / 1000$, as mentioned in many references such as [24] page 4, [6] page 28 or [12] page 79. Most documented numerical simulations analysing member behaviour for both flexural and lateral torsional buckling incorporate this magnitude for the column bow imperfection, see also the SEMI-COMP report [25].

Thus in the present paper, the magnitude of the column bow imperfection is taken as $L / 1000$ when accompanied by a residual stress pattern. When an equivalent geometrical imperfection is considered and residual stresses are accounted for through this imperfection, its magnitude varies, depending on the studied case.

The imperfections of the finite element model have been established by first performing a linear buckling analysis on the perfect prismatic column shell model with given boundary conditions, then the relevant (displacement) normalized global buckling mode is extracted. In the following non-linear (GMNIA) finite element calculations the imperfections are established by importing the normalized displacements of the lowest global buckling mode in the relevant plane of buckling, multiplying this by the maximal imperfection magnitudes and updating the nodal coordinates of the model by adding the established nodal imperfections.

\subsection{Residual stress}

The distribution and magnitude of residual stresses produced by cooling after rolling, welding or cutting are just as important as the geometric column bow imperfection. In this regard, the axis of bending and the shape of the cross-section and its size and plate thicknesses are important factors.

Residual stresses vary a great deal as they heavily depend on the fabrication process. Thus, different residual stress patterns seem to be appropriate for different regions of the world, see [26] p. 118 and [27]. As far as European I-sections are concerned, the most appropriate residual stress pattern seems to be the one adopted by Young [28], in which the residual stress distribution is parabolic both in the flanges and in the web. A similar residual stress distribution was also proposed recently by Szalai and Papp [29], which aimed at satisfying the internal equilibrium equations.

The basis for the European buckling curves and the most commonly used residual stress pattern for hot-rolled I profiles in numerical simulations is the simplified, linearized model as shown in [12]. However, parabolic distributions are also in use for numerical simulations, such as in the case of comprehensive investigative reports, where most effects dominating column and beam column behavior are calibrated from experimental results as in the SEMI-COMP report [25]. As compressive residual stresses have a negative effect on column behavior, a larger compressive area in the flanges, assuming a linear distribution, as opposed to a parabolic distribution, should lead to slightly conservative results.

In the finite element simulations presented in this paper both a linear mean residual stress distribution designated $\mathrm{R} 1$ and parabolic mean residual stress distribution designated $\mathrm{R} 2$ are

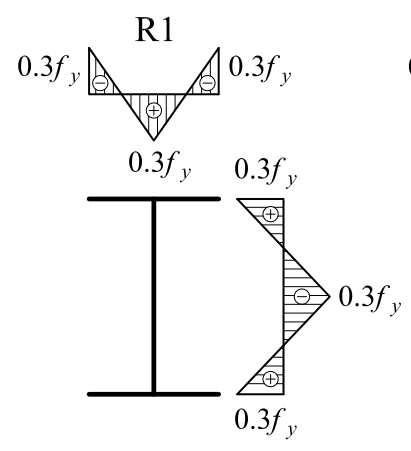

$h / b>1.2$

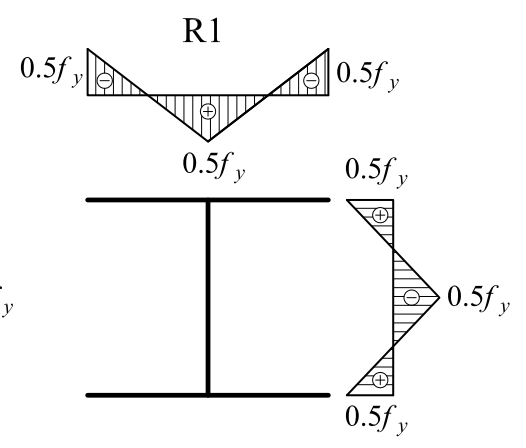

$h / b<1.2$
Figure 5: Linear residual stress distributions R1 scaled by the yield stress.

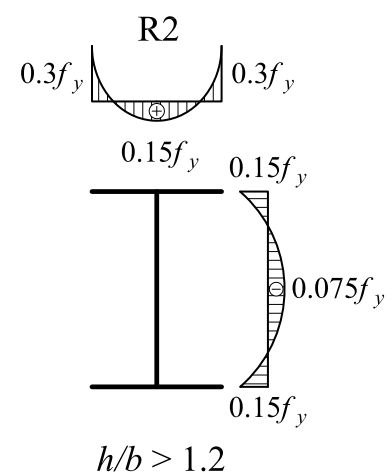

$h / b>1.2$

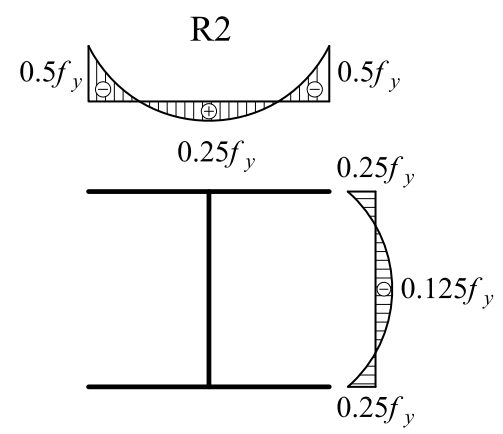

$h / b<1.2$
Figure 6: Parabolic residual Stress distributions R2 scaled by the yield stress.

used. The magnitude of the initial stress depends on height to width ratio of the section analysed. The geometry of EURONORM I-sections and thereby the magnitude of the residual stress depends on whether the height to width ratio is smaller or greater than $h / b=1.2$ as shown in [6]. The linear residual stress distributions R1 are shown in in Figure 5 and the parabolic residual stress distributions are shown in Figure 6 both scaled by the yield stress. However, as mentioned, the residual stresses ought to be independent of the yield stress. This will not have an impact on analysis performed for S235 grade steel with $f_{y}=235 \mathrm{MPa}$, which is used for most simulations. However, in the section on the influence of the yield stress this problem will be addressed further and we will use a linear residual stress distribution shown in Figure 7, which is not scaled by the yield stress.

The presented finite element simulations based on geometric column bow imperfections and a residual stress distribution are performed by including the residual stress distributions through an initial thermal loading step. The temperature change $\Delta T$ needed in a point of the cross-section depends on the thermal expansion coefficient $\beta$ and the magnitude of the residual stress $\sigma_{R}$ to be established at that point. The temperature change needed is given as

$$
\Delta T=-\frac{\sigma_{R}}{E \beta}
$$

This method of residual stress introduction can only be used for true self equilibrating residual stress distributions. Since 


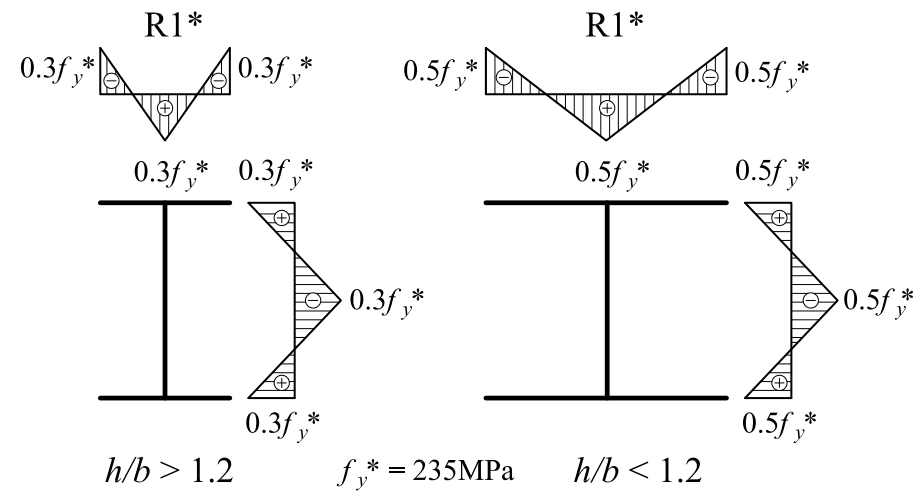

Figure 7: Non scaled linear residual stress distributions R1*.

the end cross-sections of the flanges and web are constrained to deform on straight lines there are no special end effects. It should be noted that the stress found in finite element analysis with low order elements are approximately constant within each element leading to a seemingly small deviation in edge stress. This should not lead to corrections.

\section{Analysis using bow imperfection and residual stress}

For a column in pure compression, tensile residual stresses are generally beneficial, while compressive residual stresses lead to premature yielding. This premature yielding results in a decreased stiffness and therefore lowers the capacity of the structural member. It is well known that the influence of residual stresses (along with all types of imperfections) is greatest for structural members of intermediate slenderness. Stocky members retain their plastic capacity regardless of residual stresses (due to strain hardening), while slender members buckle elastically. The intermediate slenderness range is where the structural members buckle in-elastically, at loads both below the plastic squash load and the elastic critical load. The fact that the buckling curve deviation from the perfect Euler buckling curve with a yielding cut off is greatest around a nondimensional slenderness equal of $\lambda=1$, is a consequence of the large sensitivity to non-linear material behaviour and imperfections in this slenderness range, both for flexural and lateral torsional buckling. This sensitivity has been shown both experimentally over the last decades and through in-depth probabilistic studies, see for example the papers by Szalai \& Papp [30] and Kala \& Kala [31].

\subsection{Influence of residual stress distribution}

In Figures 8 and 9 finite element results from geometric material non-linear and imperfection analysis (GMNIA) are presented in the form of flexural buckling reduction factors $\chi$ (buckling curves) for major axis buckling obtained for the two different residual stress patterns R1 and R2. The steel grade used is S235 and the profiles investigated are the IPE160, and HEB300. The IPE160 falls into buckling curve $a$ for major axis buckling, while the HEB300 falls into buckling curve $b$, mainly due to larger residual stress magnitudes. The relative deviation of the numerical results from the appropriate buckling curve are illustrated by the graph in the right hand sides of the figures. The results for varying slenderness values have been joined by straight line segments to visualize the numerically determined buckling curve.

It can be seen that the figures show the same tendency for the profiles investigated. Due to the fact that a larger area of the flange contains compressive residual stresses for the linear distribution than for the parabolic distribution and that the maximum residual compressive stress in the web is larger as seen in Figures 5 and 6, the obtained buckling curve for R1 lies slightly below the curve for R2. Furthermore, the largest deviation from the European buckling curve is clearly seen to be around a non-dimensional slenderness of $\lambda=1$. These results agree with the those presented by Boissonnade for the case of LTB [20]. While the influence of the residual stress distribution is extremely similar for both types of profiles, the overall impact on the obtained reduction factor is naturally greater for wide-flange profiles, such as the HEB300. It is concluded that the linear residual stress distribution can be used to predict accurate results and that it is slightly more conservative compared to the use of the parabolic residual stress distribution.

\subsection{Influence of residual stress magnitude}

Having illustrated the influence of the residual stresses pattern in the previous section, this section turns to the influence of the magnitude of residual stresses. The residual stress distribution for hot-rolled I-profiles is defined, in terms of magnitude, by the value of compressive residual stress at the flange tips. As stated in the introduction, experimental research performed in the 1970's into this area shows that the magnitude of residual stresses in hot-rolled and welded profiles tend to be independent of the material yield stress, both for mild and high-strength steels. This is also confirmed by experimental investigations performed on contemporary high strength steels as shown by Lee et al [19]. Nevertheless, numerical simulation results found in most references tend to refer the magnitude of residual stresses to either the material yield stress [22] or to a nominal stress of $f_{y}^{*}=235 \mathrm{MPa}$.

This subsection quantifies the difference between these two cases of residual stresses $\mathrm{R} 1$ and $R 1 *$ for various steel grades (S355, S420, S460, S690) and for two profiles with different height to width ratios. Figures 10 and 11 show the numerically obtained curves for the two profiles. On the right, the relative difference between scaling and not scaling the residual stresses with the yield stress of the material is shown. It is seen that, as expected, the carrying capacity is increasingly underestimated as the yield stress of the material is increased if the residual stresses are scaled with the yield stress, especially in the intermediate slenderness range and that the relative effect is considerably larger for the HEB300 profile.

\subsection{Influence of material stress-strain curve}

The material curve used in the numerical simulations up until this point has been the bilinear one, with a hardening slope of $E / 100$, shown in Figure 4. In this section, three other material 

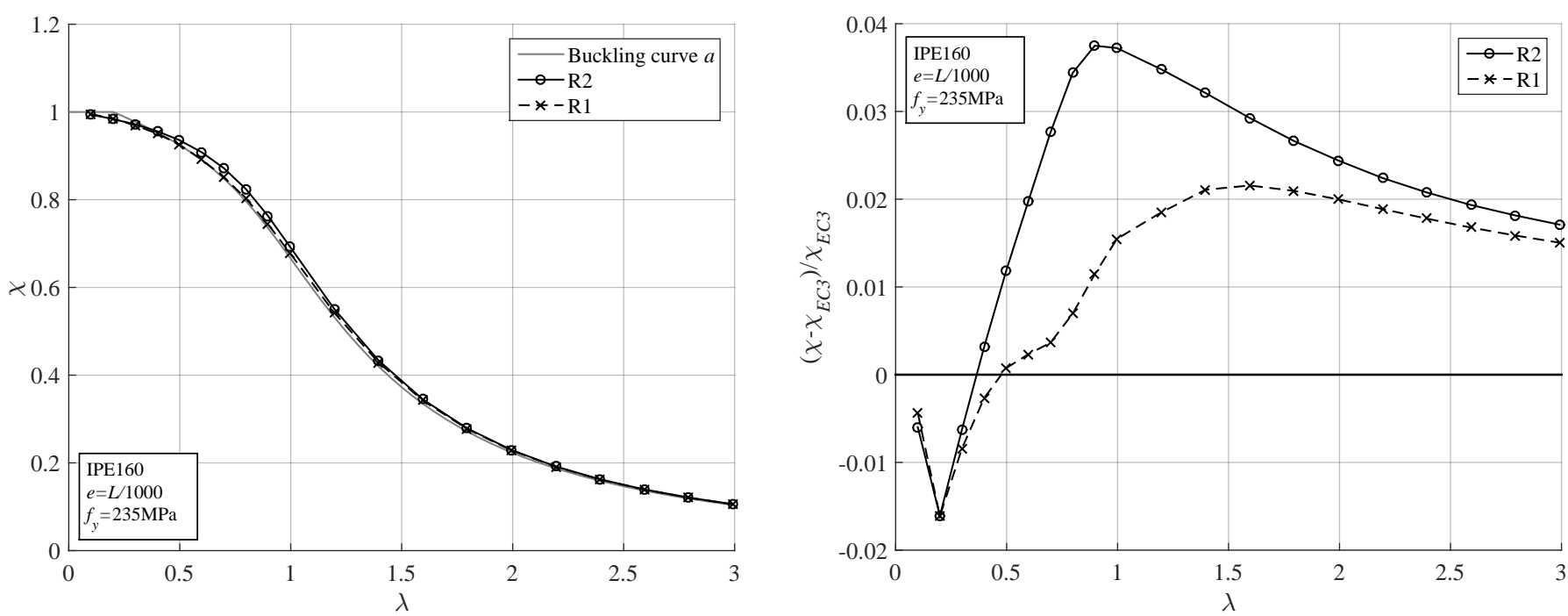

Figure 8: IPE160 with $L / 1000$ bow imperfection and R1 or R2 residual stresses compared to the Eurocode buckling curve $a$.
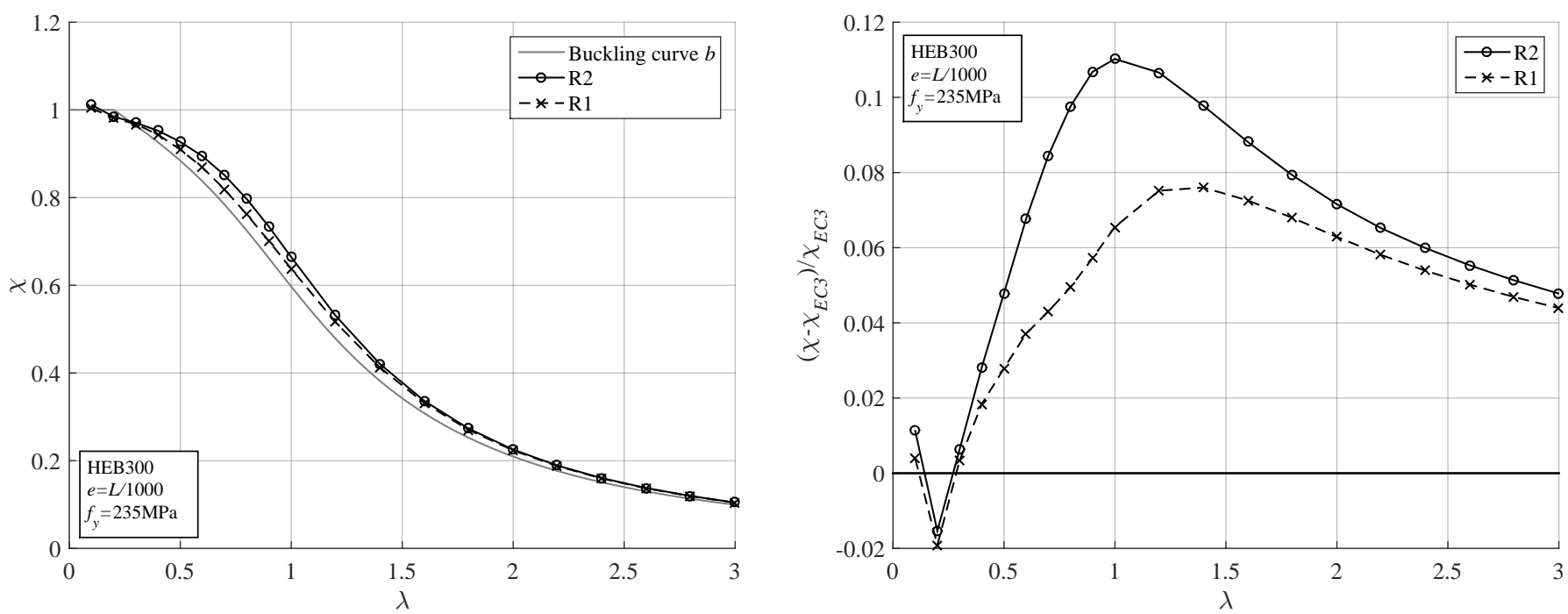

Figure 9: HEB300 with $L / 1000$ bow imperfection and R1 or R2 residual stresses compared to the Eurocode buckling curve $b$.
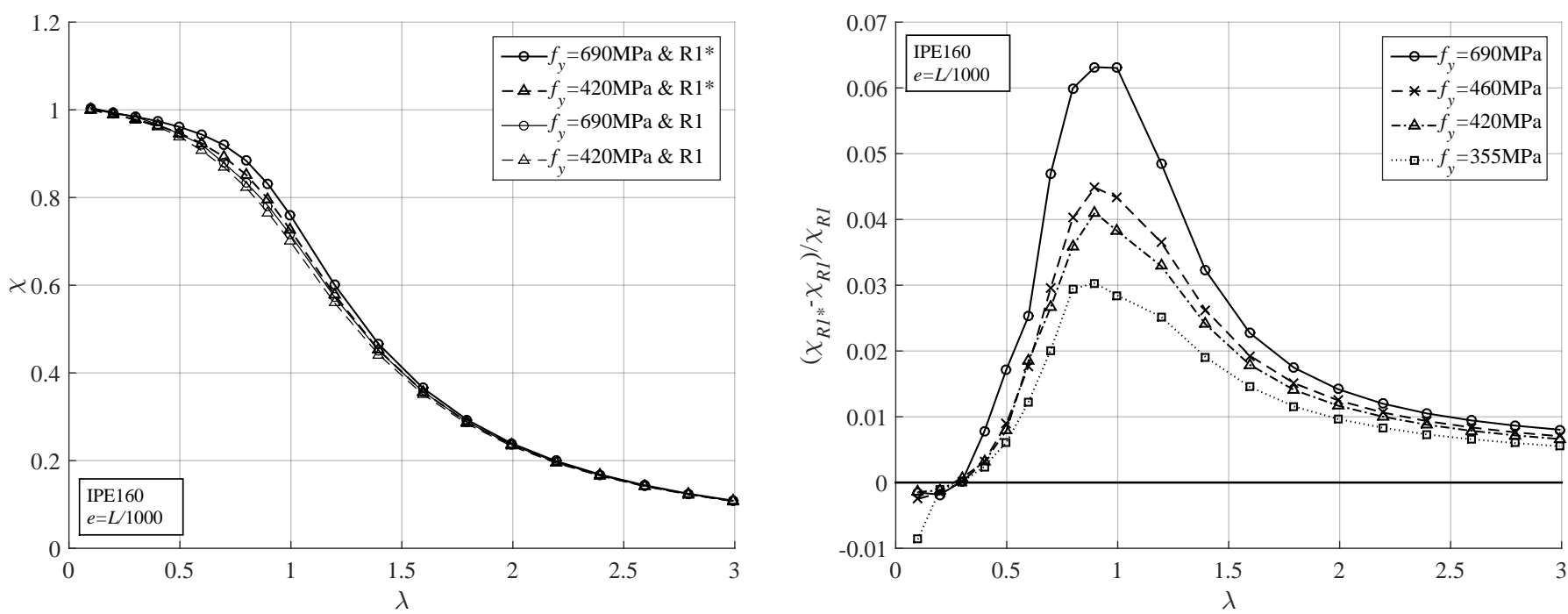

Figure 10: IPE160 with $L / 1000$ bow imperfection and R1 or R1* residual stresses compared for varying yield stress magnitudes. 

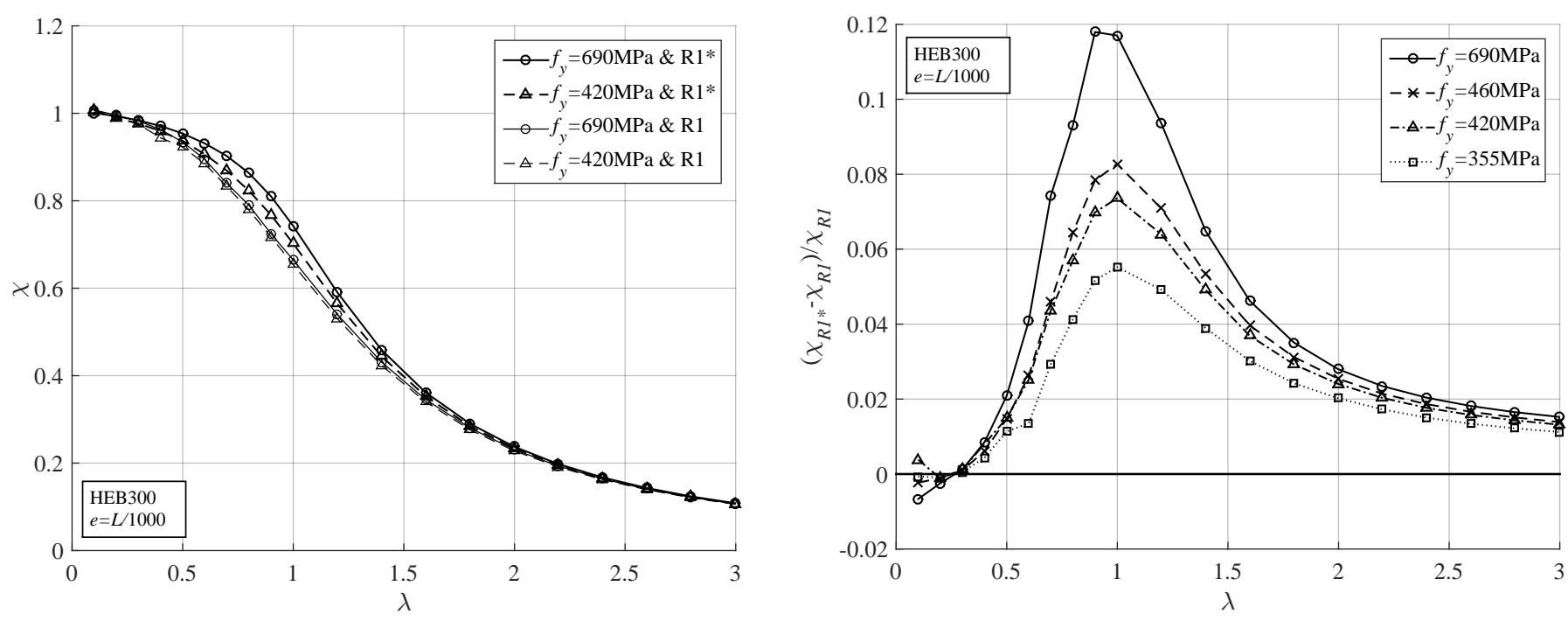

Figure 11: HEB300 with $L / 1000$ bow imperfection and R1 or R1* residual stresses compared for varying yield stress magnitudes.

\begin{tabular}{lcc}
$\begin{array}{l}\text { Material } \\
\text { property }\end{array}$ & $\begin{array}{c}\text { With prop. } \\
\text { limit }\end{array}$ & $\begin{array}{c}\text { Without prop. } \\
\text { limit }\end{array}$ \\
\hline$E$ & $210 \mathrm{GPa}$ & $210 \mathrm{GPa}$ \\
$\sigma_{p r o p}$ & $211.7 \mathrm{MPa}$ & $236.2 \mathrm{MPa}$ \\
$\sigma_{y 1}$ & $236.2 \mathrm{MPa}$ & $236.2 \mathrm{MPa}$ \\
$\sigma_{y 2}$ & $243.4 \mathrm{MPa}$ & $243.4 \mathrm{MPa}$ \\
$\sigma_{u}$ & $432.6 \mathrm{MPa}$ & $432.6 \mathrm{MPa}$ \\
$\varepsilon_{p 1}$ & 0.0040 & 0 \\
$\varepsilon_{p 2}$ & 0.0198 & 0.0198 \\
$\varepsilon_{p u}$ & 0.1817 & 0.1817
\end{tabular}

Table 2: DNV material properties for S235 true stress-strain curve.

curves are used and results are compared in order to observe the influence of these choices on the column buckling curves. The bi-linear material curve used throughout this paper is also recommended by the DNV [32] (page 18) to be used for buckling problems. Additionally, the DNV presents an alternative material curve which includes a proportionality limit at $0.9 f_{y}$. According to the ECCS Manual on Stability of Steel Structures, [6] the proportionality limit is for all practical applications meaningless and should correspond to the yield stress. In the context of numerical simulations however, the considerably reduced stiffness in the material curve proposed by the DNV between the assumed proportionality limit and the yield stress is likely to have significant effects on structural member capacity. The only available GMNIA results which include a material model with a proportionality limit is, to the authors knowledge in the PhD dissertation by Offner [33] (page 228). In this work a comparison between a elastic-perfect plastic material model and a material model which includes a proportionality limit of $0.8 f_{y}$, a yield plateau and linear strain hardening shows that using the latter material curve results in lower capacities, in all cases.

In order to isolate the specific effect of introducing a propor-

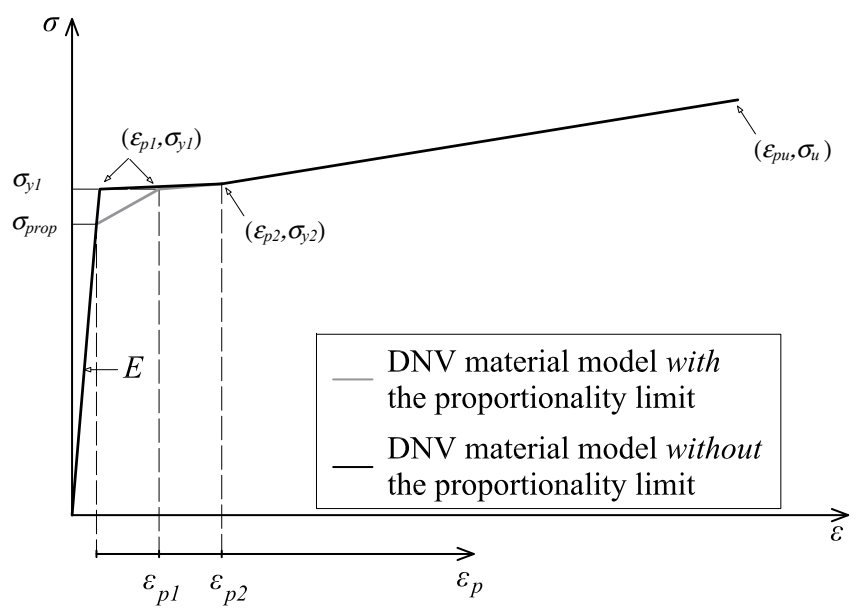

Figure 12: DNV material curve with and without a proportionality limit for steel grade S235.

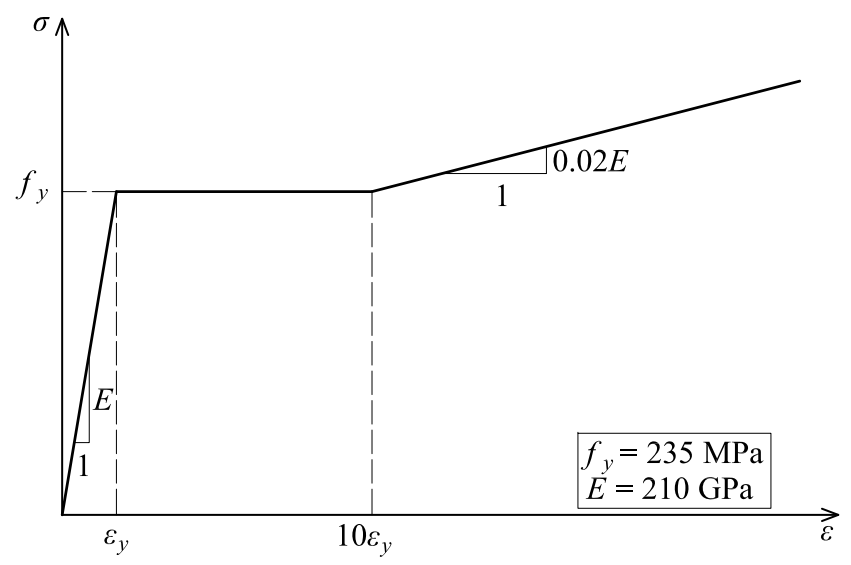

Figure 13: Trilinear material curve with a yield plateau for steel grade S235. 
tionality limit, the DNV curve with and without a proportionality limit is included in the GMNIA investigation and it is shown in Figure 12 with the material properties from Table 2. Furthermore, the influence of having a yield plateau is also studied by performing numerical simulations using a tri-linear stress-strain curve, shown in Figure 13.

Figures 14 and 15 show the results of GMNIA finite element analysis for an IPE160 and a HEB300 Profile respectively. No significant difference is seen, with respect to differences in strain hardening or having a yield plateau. This is most likely due to the fact that the plastic strain is too small for strain hardening to have a noticeable influence. This difference might become somewhat more noticeable in the post-buckling range of class 4 sections and especially in the low slenderness range.

The curve obtained when using a proportionality limit lies considerably lower than the other curves. The difference increases as plastic behavior becomes more pronounced and is very small in the high slenderness range, where the maximum attainable load approaches the elastic critical load, as shown in the right hand side plots of the Figures 14 and 15.

\subsection{Influence of yield stress}

Recent numerical simulations, which deal with the influence of yield stress on reduction factors, are quite sparse and are usually part of a considerably wider parametric study, both for columns (flexural buckling) and beam-columns (lateraltorsional buckling). This is mainly due to the fact that most finite element GMNIA investigations are performed on the standard, S235 steel grade. When results are available however, the influence of yield stress is barely touched upon. One may for example refer to [22], where no influence of yield stress on the LTB reduction factor was found. In this case however, the residual stresses were probably assumed to scale with yield stress. Another investigation by Offner [33] (see page 232) succinctly addressed this issue, in the context of beam-columns loaded in compression and biaxial bending. From Offner's work one can observe the influence of yield stress from the normalized $N, M_{y}, M_{z}$ interaction diagrams for the classical column case by considering data points corresponding only to the pure compression load case. The conclusion found by this observation is that a change in yield stress definitely has an influence on the flexural buckling curves.

In this section, finite element GMNIA results are presented in the context of quantifying the influence of yield stress alone. A bow imperfection of $L / 1000$ and a non-scaling, linear residual stress distribution ( $\mathrm{R} 1 *$ ) is assumed. The residual stress pattern and magnitude are discussed in subsections 4.1 and 4.2. The two profiles investigated are the IPE160 and HEB300. Furthermore, 5 different steel grades are studied: the classical S235 mild steel, S355, S420, S460 and S690. In Eurocode the EN 1993-1-12, [34], specifies that steel grades from S460 to S700

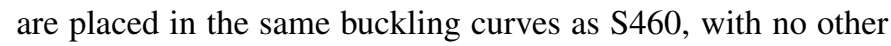
differences being made in the context of member stability. The benchmark case considered in this section is the S235 steel grade, to which results for other steel grades will be related and compared to.
Figures 16 and 17 show that a gradual increase in yield stress results in a gradual lifting of the buckling curves. The effects are more pronounced in the wide-flange profile due to the higher relative magnitude of residual stresses. 

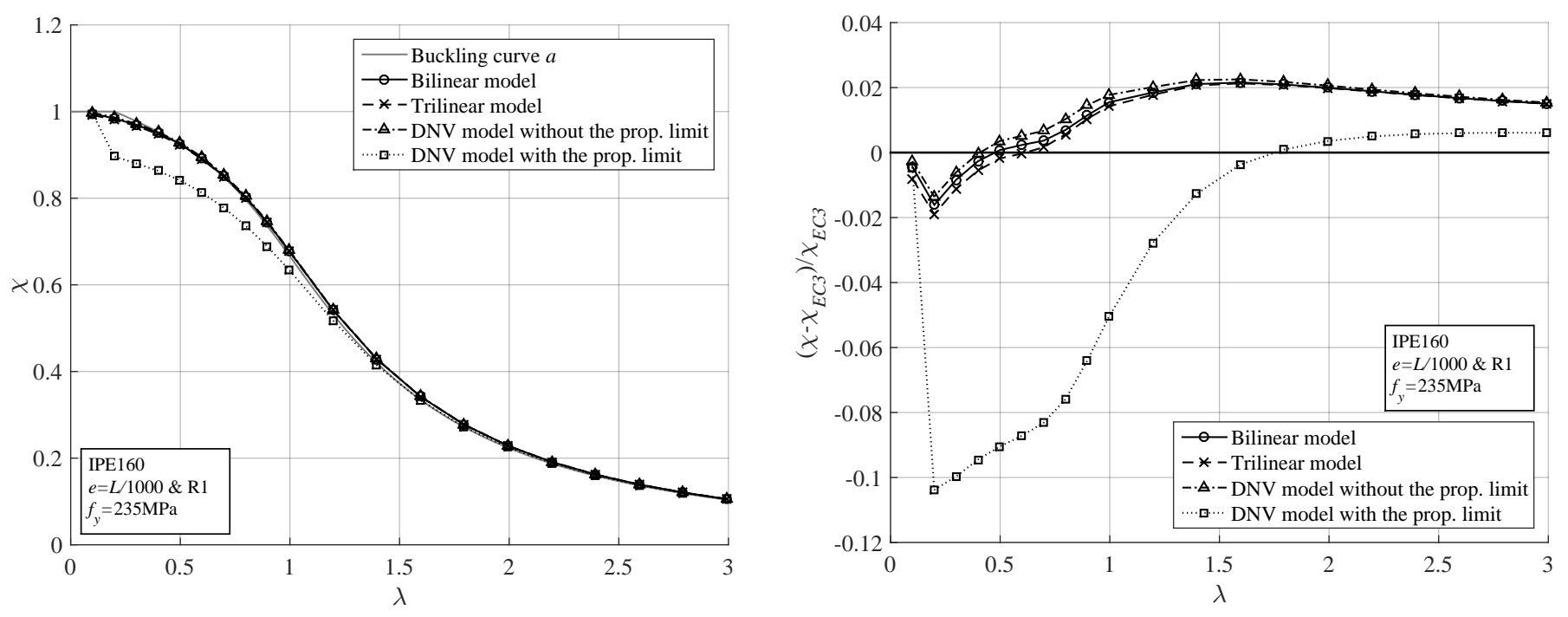

Figure 14: IPE160 with $L / 1000$ bow imperfection and residual stresses R1 for various material curves.
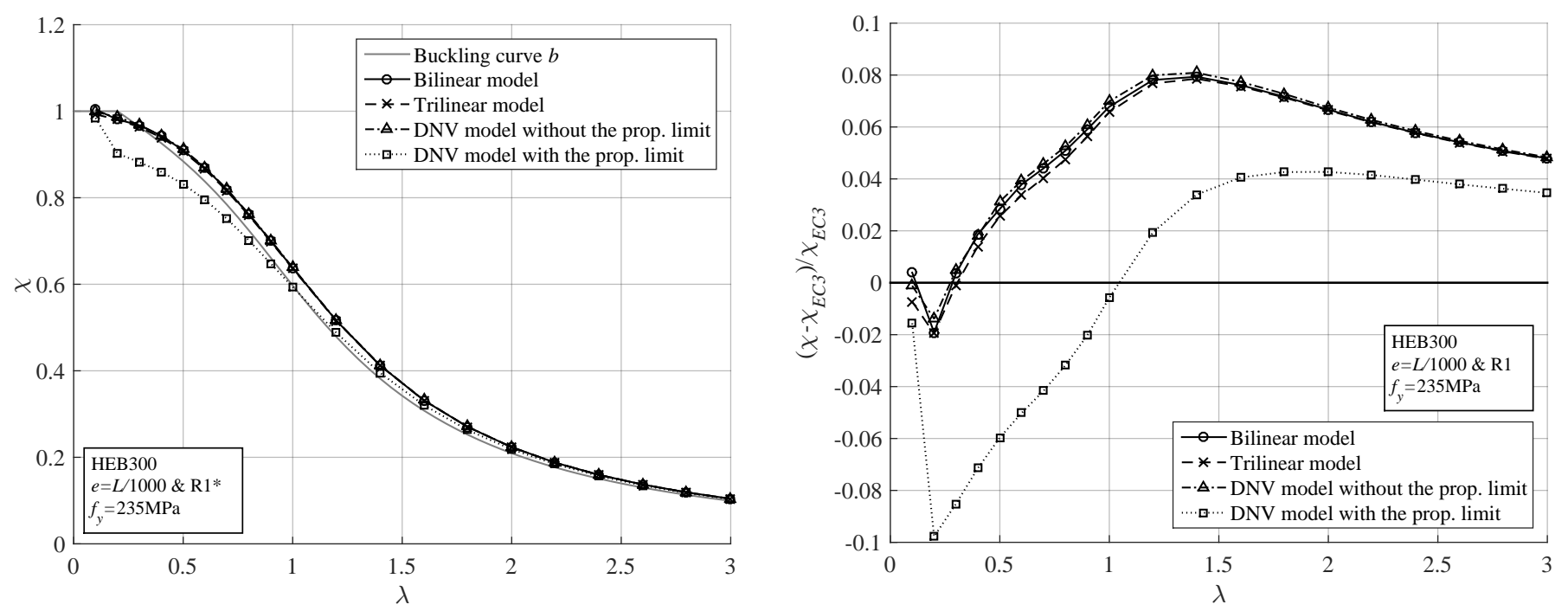

Figure 15: HEB300 with $L / 1000$ bow imperfection and residual stresses $\mathrm{R} 1$ for various material curves. 

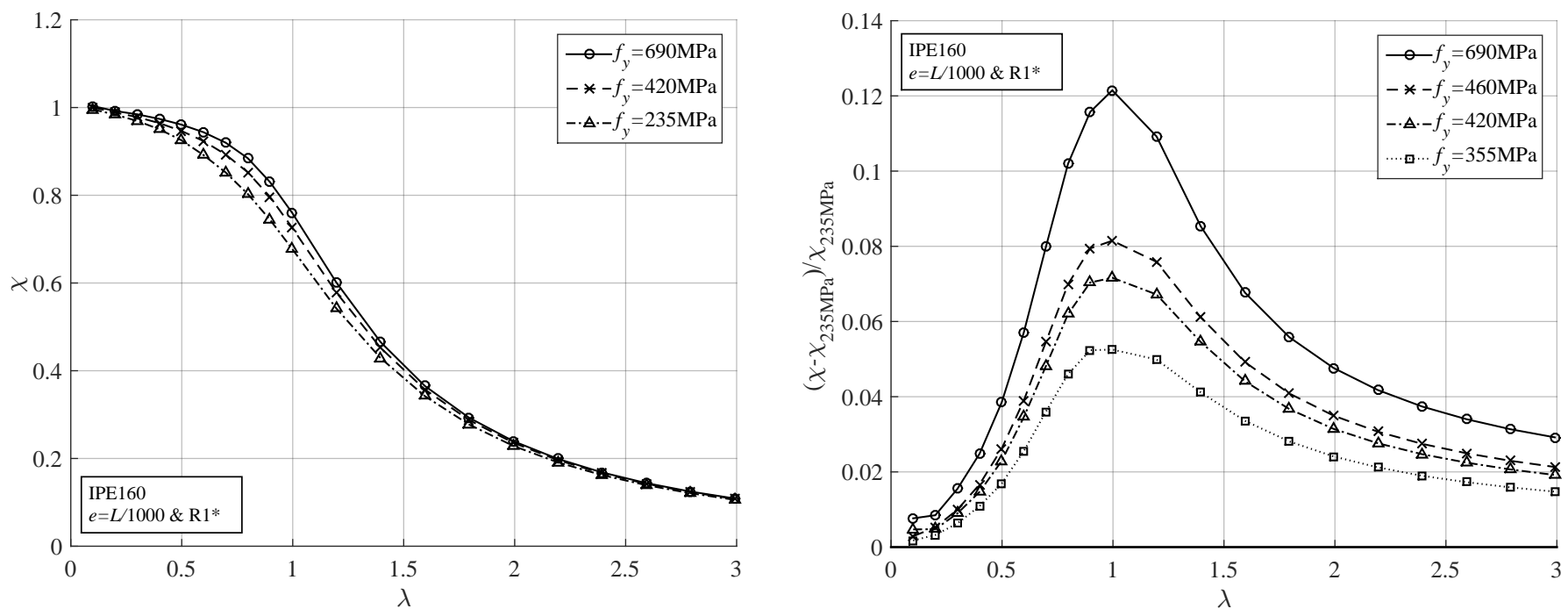

Figure 16: IPE160 with $L / 1000$ bow imperfection and residual stresses R1* for various steel grades.
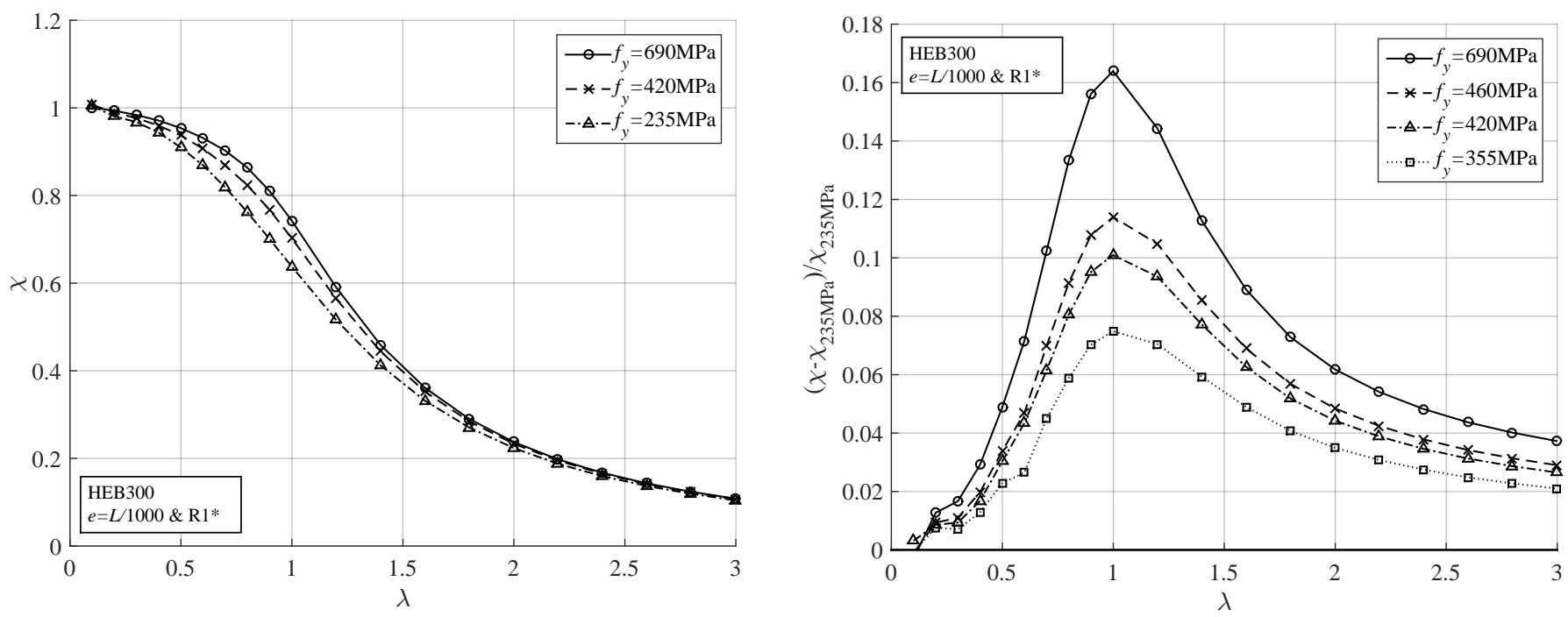

Figure 17: HEB300 with $L / 1000$ bow imperfection and residual stresses R1* for various steel grades. 


\section{Analysis using equivalent geometric imperfection}

The aim of this section is to provide an overview of the use of equivalent geometric imperfection $e_{e q}$ to provide numerical simulation results, based on the two evident possibilities that come into play for the choice of the imperfection magnitude. First of all, as shown in equations (1) and (6), once the shape dependent normalized equivalent imperfection magnitude $e / k$ is known then the expression for buckling curve $\chi$ is only a function of the relative slenderness and this controls the influence of the imperfection on the structural member in the Eurocode Ayrton-Perry formulation. The two possibilities that come into play are: As recommended in Eurocode 3, the equivalent imperfection, which accounts for the combined effects of residual stress and geometric imperfection by means of an enhanced geometric imperfection, can be expressed as a fraction of the member length as

$$
e_{e q}=\frac{L}{\xi}
$$

where the fraction of $L$ is given in Table 5.1 of [14] and thus $\xi=$ $L / e_{e q}$ is a given constant for each buckling curve. Alternatively the equivalent imperfection could be extracted directly from the Ayrton-Perry formulation as

$$
e_{e q}=\alpha(\lambda-0.2) k
$$

which clearly is a function of the relative slenderness, (yield stress dependent). In order to illustrate and compare this alternative equivalent imperfection to the former, it can also be expressed as a fraction of the member length $e_{e q}=L / \xi$, where $\xi$ is then given by

$$
\xi=\frac{L}{\alpha(\lambda-0.2) k}
$$

The equivalent imperfection magnitudes used in the following are given in Table 3, which is based on the plastic case and use of $k=W_{p l} / A$. The two possibilities are illustrated using the ratio $\xi=L / e_{e q}$ by plotting the related analytical expressions in Figure 18, for buckling curves $a, b, c, d$. The first set (imperfection) curves are the ones that correspond to the current buckling curves. The plateau present in the buckling curves for $\lambda \leq 0.2$ results in $e_{e q}$ becoming zero at $\lambda=0.2$, shown in the figure as $\xi$ approaching infinity. The second set of curves are based on the prescribed Eurocode 3 values for the equivalent imperfection found in Table 5.1 of EC3 [14] and also shown in the Table 3 as constant fractions of the member length. Figure 19 shows

\begin{tabular}{cccc}
$\begin{array}{c}\text { Buckling } \\
\text { curve }\end{array}$ & $\begin{array}{c}\text { Extracted } \\
\text { from EC3 eq. (9) }\end{array}$ & $\begin{array}{c}\text { Table 5.1 } \\
\text { in EC3 [14] }\end{array}$ & $\begin{array}{c}\text { Table 5.5.1 } \\
\text { in ENV [13] }\end{array}$ \\
\hline$a$ & $\alpha_{a}(\lambda-0.2) k$ & $L / 250$ & $L / 600$ \\
$b$ & $\alpha_{b}(\lambda-0.2) k$ & $L / 200$ & $L / 380$ \\
$c$ & $\alpha_{c}(\lambda-0.2) k$ & $L / 150$ & $L / 270$ \\
$d$ & $\alpha_{d}(\lambda-0.2) k$ & $L / 100$ & $L / 180$
\end{tabular}

Table 3: Equivalent imperfection magnitudes $e_{e q}$ for plastic capacities. the analytical buckling curves obtained using all these equivalent geometrical imperfections and those from the early ENV [13]. The values given in Table 3 for the ENV are for weak axis buckling and they have been found by disregarding the safety factor influence. For major axis buckling the ENV does indeed as mentioned in the introduction prescribe equivalent imperfections extracted from the buckling curves.

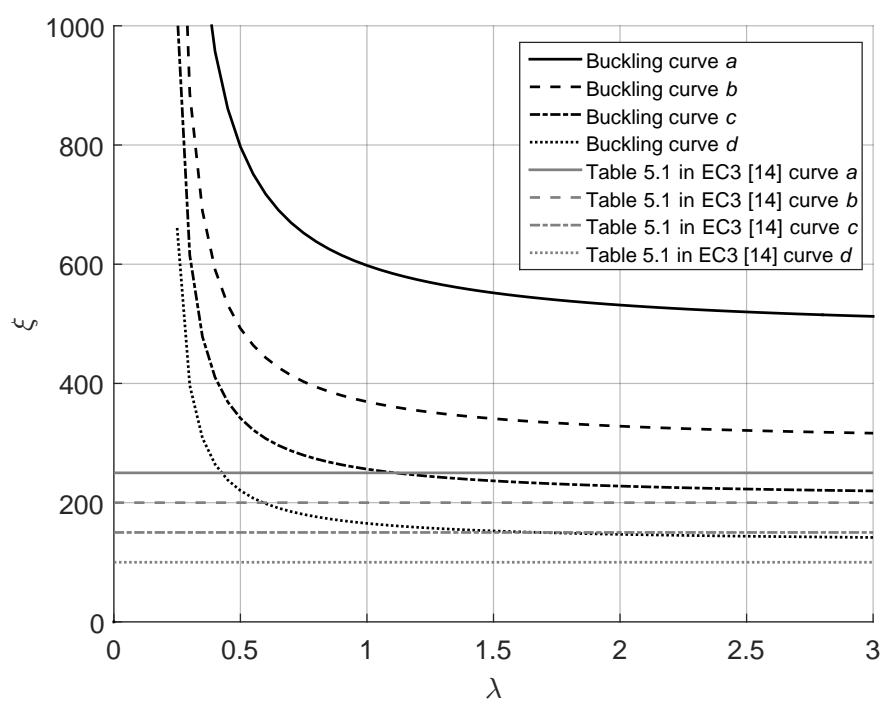

Figure 18: Analytical curves for the imperfection parameter $\xi$ as a function of slenderness.

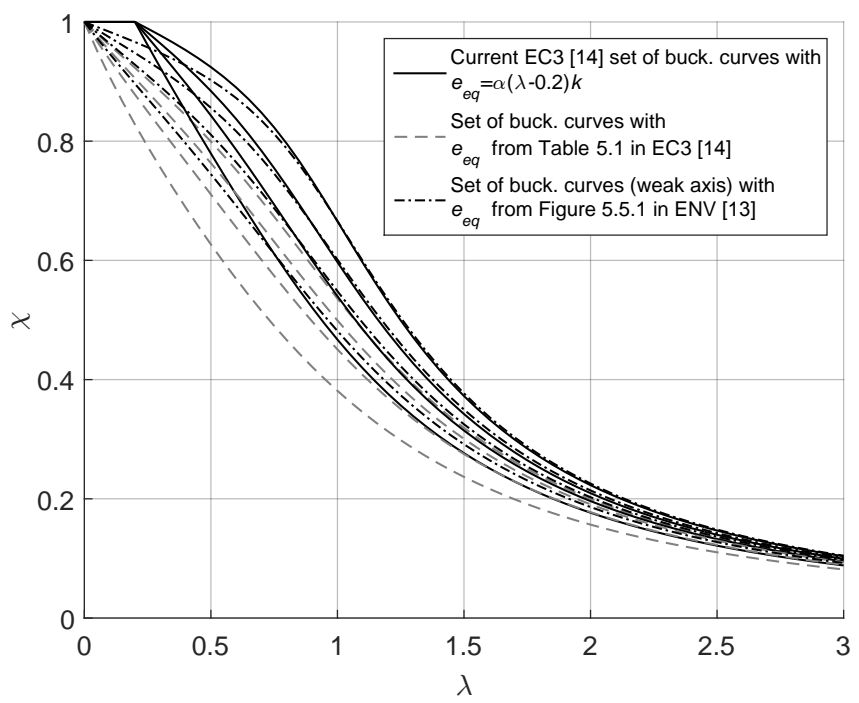

Figure 19: Analytical derived Ayrton-Perry buckling curves dependent on the equivalent imperfection used.

\subsection{FE simulation with equivalent geometric imperfections}

Figures 20 and 21 present the buckling "curves" found by finite element GMNIA analysis for the IPE160 and HEB300 profiles using the two alternative equivalent imperfections for S235 grade steel. The finite element simulations clearly show the extent to which a too large global bow imperfection results 

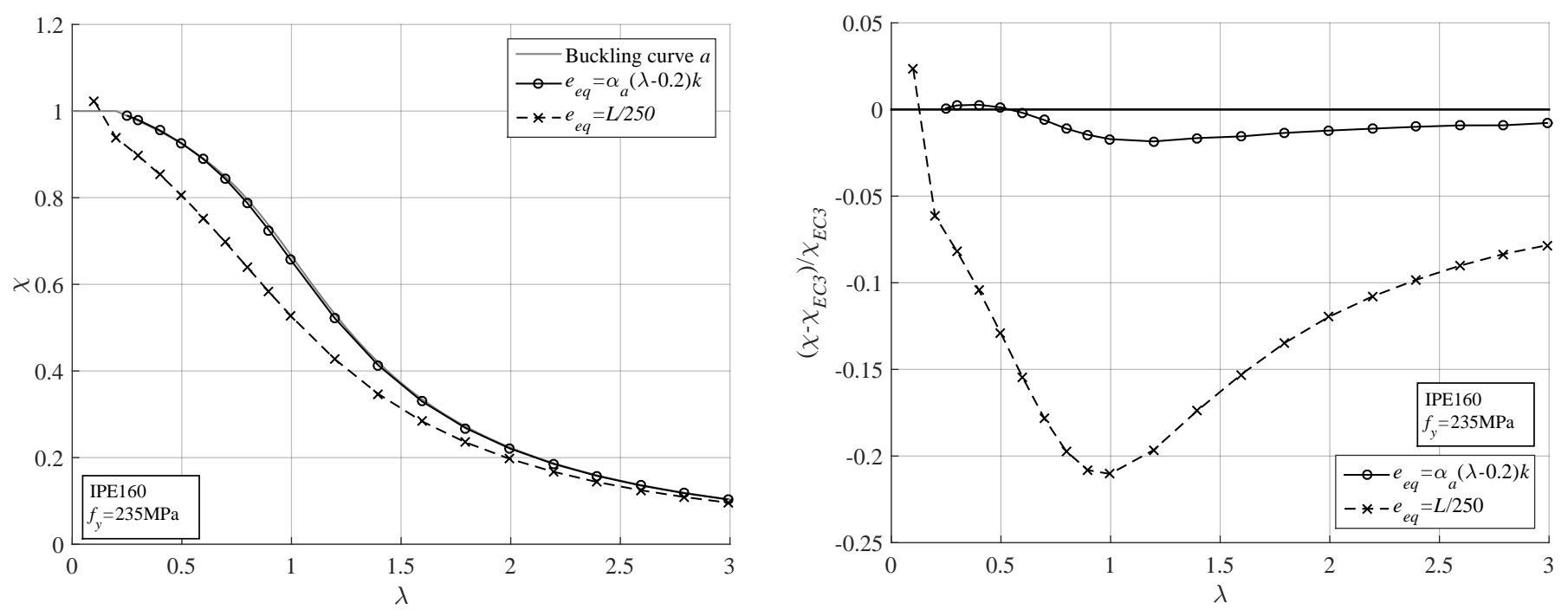

Figure 20: IPE160 with the two equivalent imperfections for S235 grade steel.
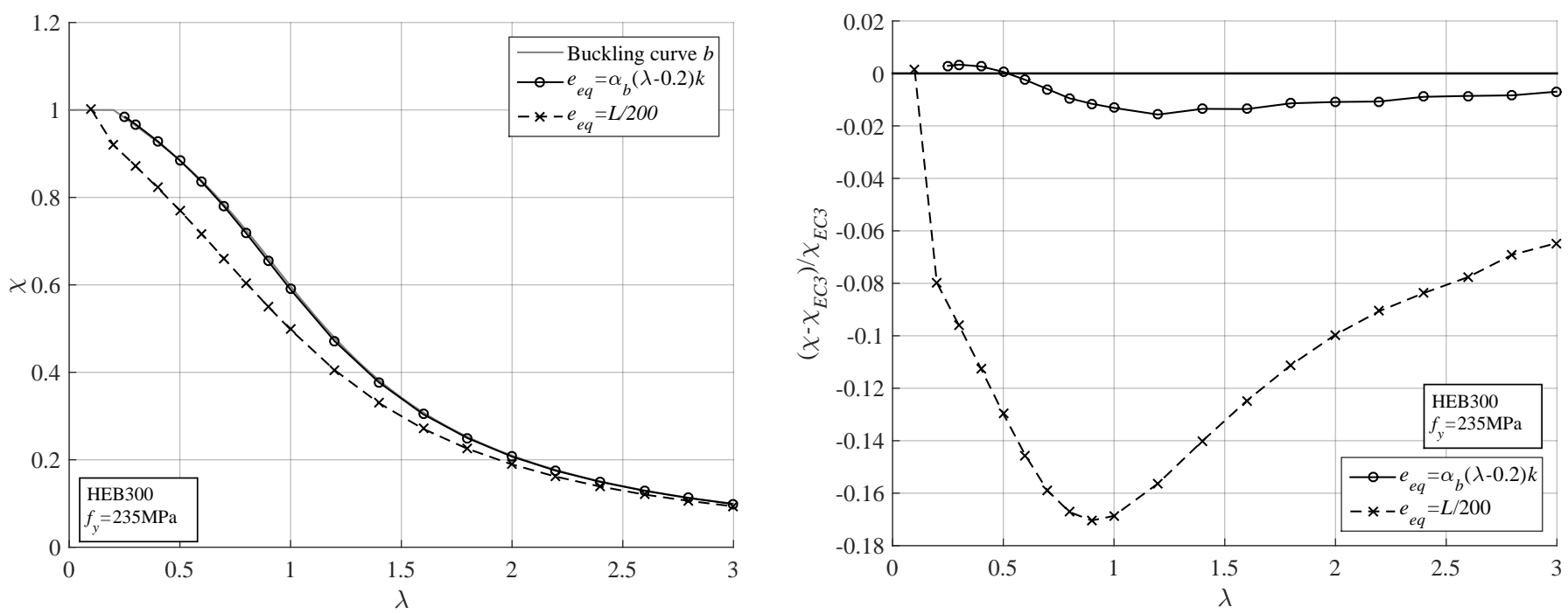

Figure 21: HEB300 with the two equivalent imperfections for S235 grade steel. 


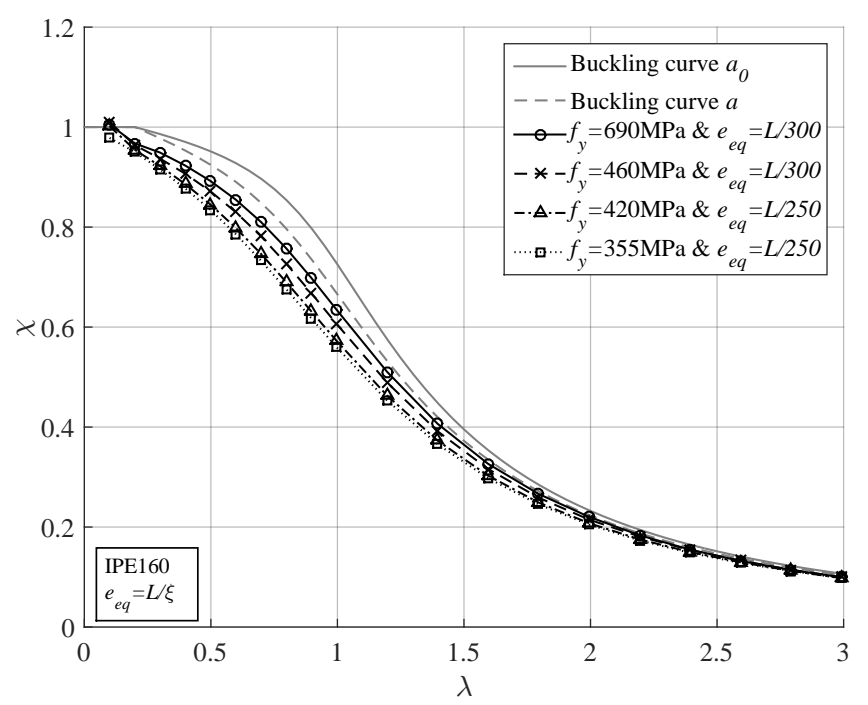

Figure 22: IPE160 with equivalent imperfection as fraction of member length for different steel grades.

in a significant lowering of the buckling curves. The results shown are fully consistent with the analytically derived buckling curves shown in Figure 19. Moreover, the results are similar for all profiles and the large sensitivity to imperfections around a non-dimensional slenderness of one is again seen. Finally, the numerically simulated curves almost coincide with the analytical buckling curves, when the equivalent geometrical imperfection is extracted from the buckling curve.

\subsection{Influence of yield stress}

The influence of yield stress was assessed in subsection 4.4, in the context of using both geometrical and mechanical imperfections (residual stresses) in the numerical simulations. It was shown that an increase in yield stress does indeed raise the numerically obtained buckling curve. It can also be shown that this is also the case if the residual stresses are considered to scale with the yield stress. In this subsection, the influence of the yield stress is treated in the context of using equivalent geometrical imperfections given as fractions of the column length in finite element GMNIA simulations.

When considering the equivalent imperfection as a constant fraction of member length, as prescribed in Table 5.1 of EC3 [14], it can be seen the simulations clearly show a dependency on the steel grade. For the IPE160 this is shown in Figure 22 in which we have included the relevant buckling curves $a$ and $a_{0}$ for comparison. For the HEB300 Profile it is shown in Figure 23 where the relevant buckling curves $b$ and $a$ are included for comparison. The difference is also non-negligible, when residual stresses are accounted for through the equivalent imperfection. When using an equivalent geometrical imperfection, which accounts for all geometrical and mechanical imperfections, two possibilities arise: The imperfection can be expressed as a constant fraction of member length or extracted from the appropriate (Ayrton-Perry) buckling curve; the former, currently present in the Eurocode is advantageous due to

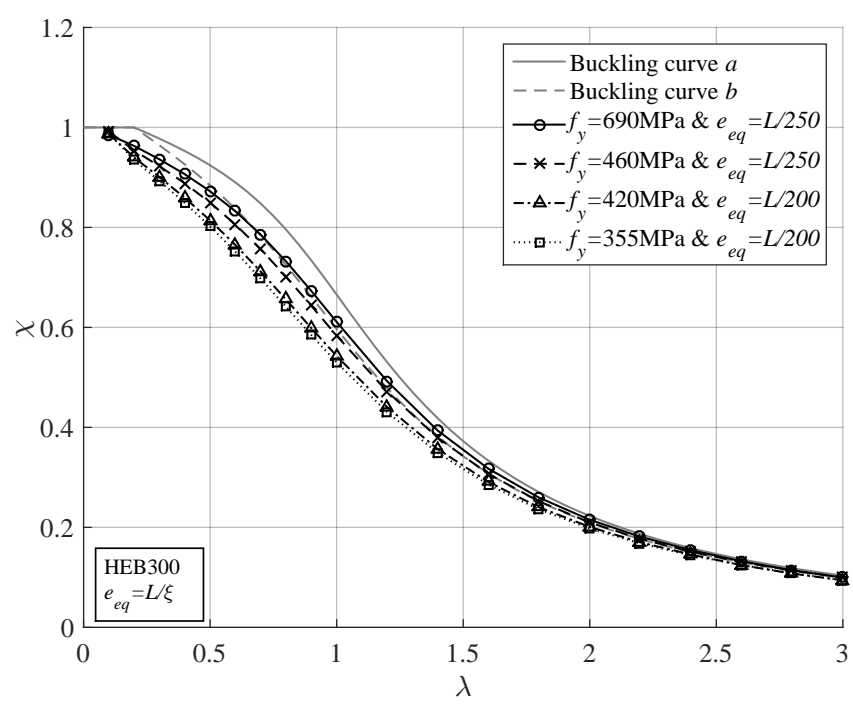

Figure 23: HEB300 with equivalent imperfection as fraction of member length for different steel grades.

its simple format. Its disadvantage lies in the fact that its magnitude is too high and therefore the obtained buckling curve is too conservative. The main advantage of using the extracted imperfection is that the appropriate buckling curve is correctly reproduced, however the real influence of yield stress is determined indirectly by the choice of buckling curve.

\section{Discussion of the imperfection formulation}

This section aims at addressing the issues pointed out in this paper regarding the use of geometrical imperfections as well as the influence of the steel grade (yield stress magnitude) and a slightly modified imperfection formulation is suggested. It has been shown that a lack of consistency is present between the current Eurocode 3 magnitude of equivalent geometrical imperfections to be used in finite element modelling and the equivalent geometrical imperfections which form the basis of the European buckling curves, the former resulting in a considerable lowering of the curves. Furthermore, no clear background seems to be available concerning the choice of column length ratios assigned to each buckling curve. The consistency report, [24] (see page 30), discusses the imperfection magnitudes and from this work the following possible solution can be proposed: The equivalent imperfection magnitude can be extracted from each buckling curve at a relative slenderness ratio of one, since columns are most sensitive to imperfections around this relative slenderness value. However, even the use of this level of imperfection will lead to deviations and a changed shape of the upper part of the buckling curve, which is not consistent with the current buckling curves, since it will not have a plateau for $\lambda \leq 0.2$.

Regarding the use of equivalent geometrical imperfections as extracted from the buckling curves, the main problem seems to be that the yield stress influence is not accounted for. Considering the tremendous amount of work put into the establishment of the European buckling curves, it is somewhat surprising that 
rather few investigations went into determining to what extent placing different steel grades on the same curve would penalize higher strength steels. The high strength steels are penalized due to neglecting two effects. First of all the diminishing relative magnitude of residual stresses for increasing steel grade raise the curves and secondly an increase in yield stress itself slightly raises the buckling curves. These two effects raise the buckling curves with increasing steel grade.

As mentioned in the introduction, the paper by Dwight [5] provides an excellent overview on the use of the Ayrton-Perry as a basis for the buckling curves. Indeed, this format was later adopted, as the European buckling curves were established based on the semi-theoretical approach, moving away from the earlier tabulated format. The overall differences for each buckling curve and their associated equivalent imperfection between the two formats are exemplarily shown and discussed in the works of Dwight [5] and Taras \& Greiner [35]. In 1975, one of the drawbacks of the tabulated curves at that time was, as mentioned by Dwight, that the higher grades of steel would be automatically penalized by forcefully placing all grades of steel on the same buckling curve. The issue was also addressed later by Maquoi [36], who suggested slightly altering the expression for the equivalent geometrical imperfections underlying the buckling curves. This was to some degree taken care of by introducing buckling curve $a_{0}$ allowing higher grade steels to move one curve up. Even though higher strength steels jump one curve, placing a group of steel grades on the same buckling curve will always penalize the higher strength steels in that group (that is the reason why results are shown in this paper for S420 and S690, as they represent "upper bounds" for the two separate groups representing steel grades up to S420 and steels grades from S460 up to S700). Furthermore, it is important to note that the use of high-strength steel has increased significantly since the seventies, due to decreasing fabrication costs, and lower weight of strength dependent structures, see f.ex. [37]. Thus, the possibility of higher grades of steel being penalized has more implications nowadays, compared to previous decades.

From a theoretical point of view, the placement of several steel grades on the same curve eq. (1) is not possible, since $\lambda$ depends on the yield stress and enters the expression, which is non-linear in $\lambda$. As mentioned imperfections have historically been expressed as a fraction of the column length implying that the imperfections $e / k$ are independent of the yield stress. If this is true and we want to keep this simplifying assumption then the expression for the imperfections should be independent of the yield stress as in equation (4). Clearly the equivalent imperfections used in the Eurocode 3 for the buckling curves in eq. (6) are dependent on the relative slenderness and thereby inversely proportional to the square root of the yield stress. The square root dependency of the imperfection on the steel grade could be removed by the introduction of the material parameter $\varepsilon$, as in equation (4) and (5). The magnitude of residual stresses in rolled profiles is generally assumed to be independent of yield stress as discussed in Section 4.2. With an increase in yield stress and moving towards high-strength steel, the manufacturing process tends to be more closely controlled, i.e. if anything one should think that, the geometrical and mechanical imperfections would decrease. One of the aims of using the AyrtonPerry formula as a basis for the buckling curves was that, in that format, it would allow for different curves, depending on the yield stress. While the current buckling curves were indeed established based on the Ayrton-Perry formula, the influence of the yield stress was deliberately omitted, for simplicity reasons [24].

Thus it is suggested (for consideration) that the theoretical (and practical) influence of yield stress on the buckling curves be introduced simply by including the $\varepsilon$ term in the expression for the imperfection as follows

$$
\begin{aligned}
e & =\alpha(\lambda \varepsilon-0.2) k \\
& =\alpha\left(\frac{L}{i} \sqrt{\frac{f_{y}^{*}}{\pi^{2} E}}-0.2\right) k \text {, where } \varepsilon=\sqrt{f_{y}^{*} / f_{y}}
\end{aligned}
$$

In which the notation $f_{y}^{*}=235 \mathrm{MPa}$ is used for the reference steel yield stress. Thus, the imperfection becomes independent of the yield stress but dependent on the slenderness $L / i$ (not relative slenderness) and the buckling curves raise automatically dependent on the steel grade. Since this equation gives the same buckling curves for the reference steel grade S235 grade steel as the Eurocode it is also suggested to keep the values of the imperfection parameters $\alpha$ unchanged. A very similar approach with $\varepsilon=\left(f_{y}^{*} / f_{y}\right)^{0.8}$ was suggested by Maquoi [36] in 1982 with slightly modified imperfection factors.

The suggested modified set of buckling curves compared to the current European buckling curves are shown in Figure 24, 25 and 26 for respectively S420, S460 and S690 grade steel. In Figure 24 we only include the set of four curves $a, b, c, d$ since these curves are used up to and including S420 grade steel, whereas in Figures 25 and 26 we include the set $a_{0}, a, b, c$, since these curves are used for steel grades higher than $\mathrm{S} 420$. It can be seen that the choice of letting higher steel grades jump a curve seems reasonable, however with the increasing steel

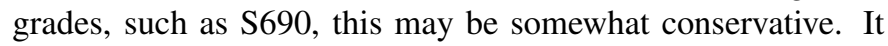
can be seen that the buckling capacity of high strength steels may be raised depending on the buckling curve and steel grade by using the modified suggestion.

In this paper and in numerous others, a column model with an imperfection of $L / 1000$ and a residual stress distribution $\mathrm{R} 1 *$ has been used and assumed to represent a realistic column. We have used these assumptions in order to support the proposed modified buckling curves. Figures 27, 28 and 29 show finite element GMNIA results for various steel grades for the IPE160, IPE500 and HEB300 profiles, respectively corresponding to modified buckling curves $a, a$ and $b$. The GMNIA results are compared to the modified buckling curves in the right hand graphs of the figures. In the left hand graphs the results may be compared visually to the relevant Eurocode 3 buckling curves. For IPE160 and IPE500 profiles the EC3 buckling curve $a$ is used for steel grades up to S420 and curve $a_{0}$ is used for steel grades above S420. For the HEB300 EC3 curve $b$ is used up to steel grade S420 and curve $a$ is used for steel grades above S420. It can be seen that the proposed modified buckling curves reflect the finite element results. 

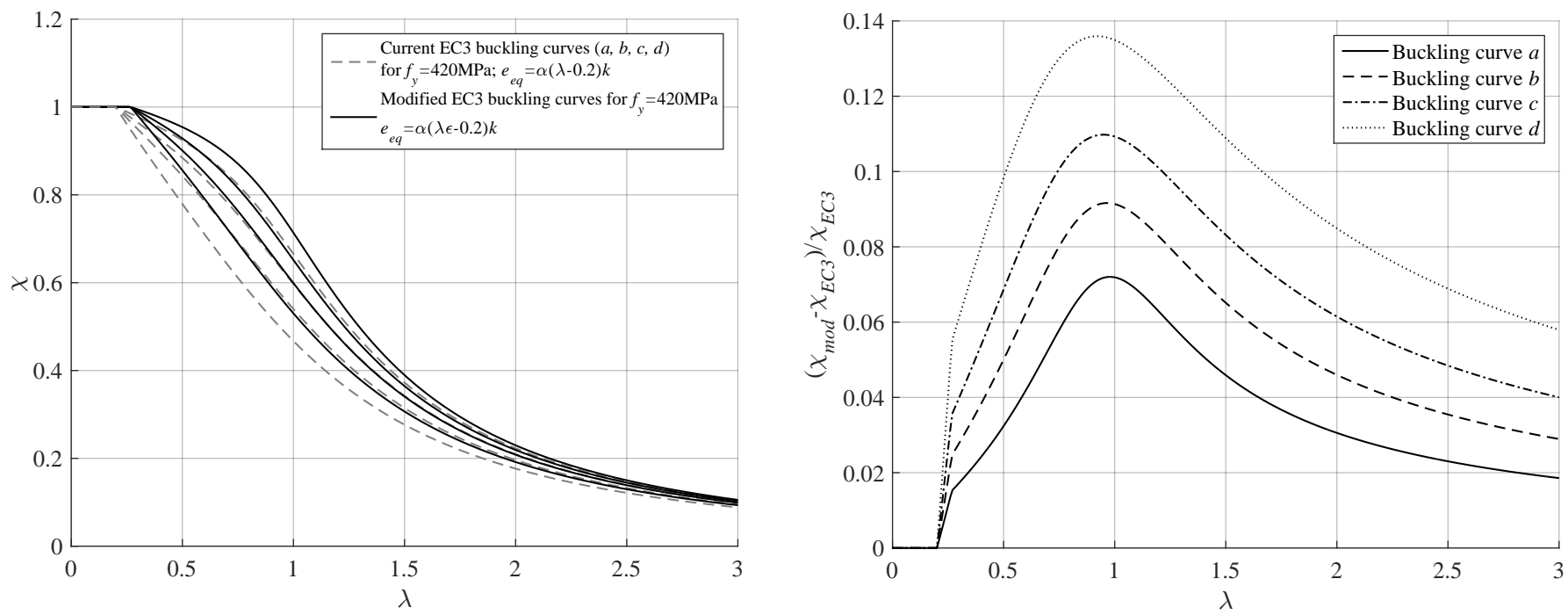

Figure 24: Suggested modified buckling curves for S420 compared to current curves $a, b, c, d$.
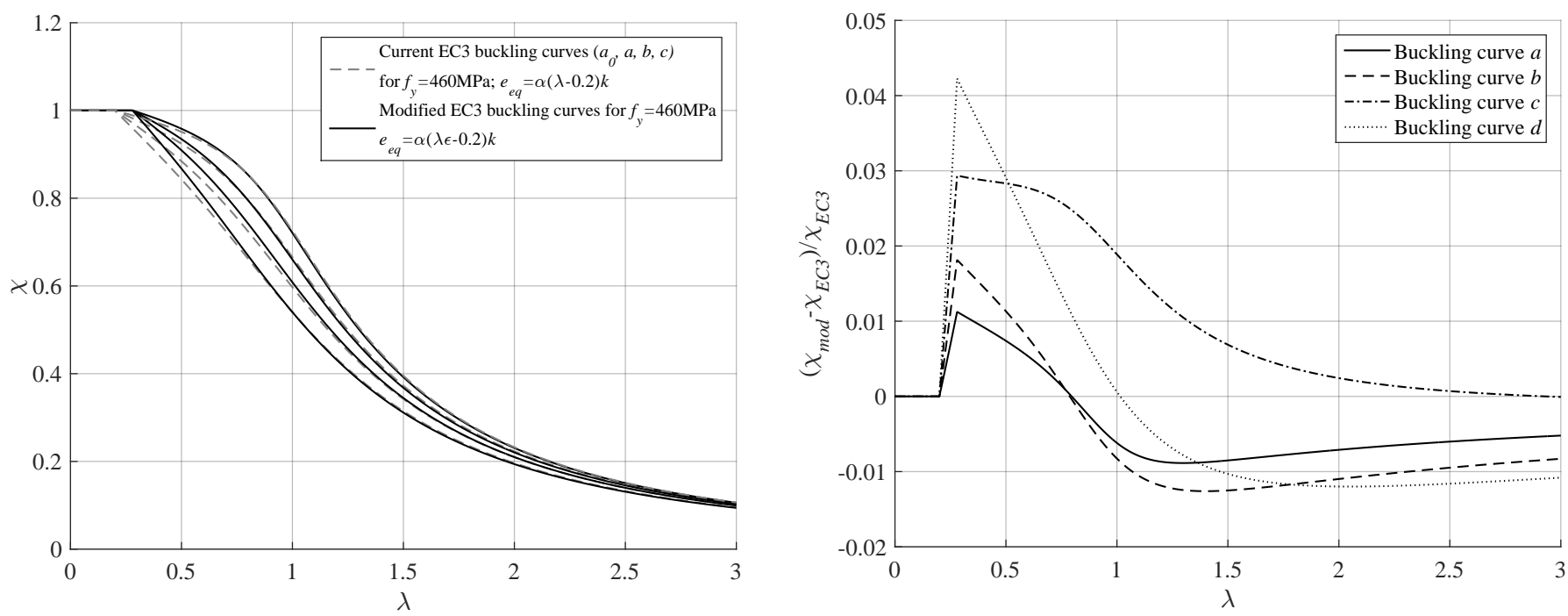

Figure 25: Suggested modified buckling curves for $\mathrm{S} 460$ compared to current curves $a_{0}, a, b, c$. 

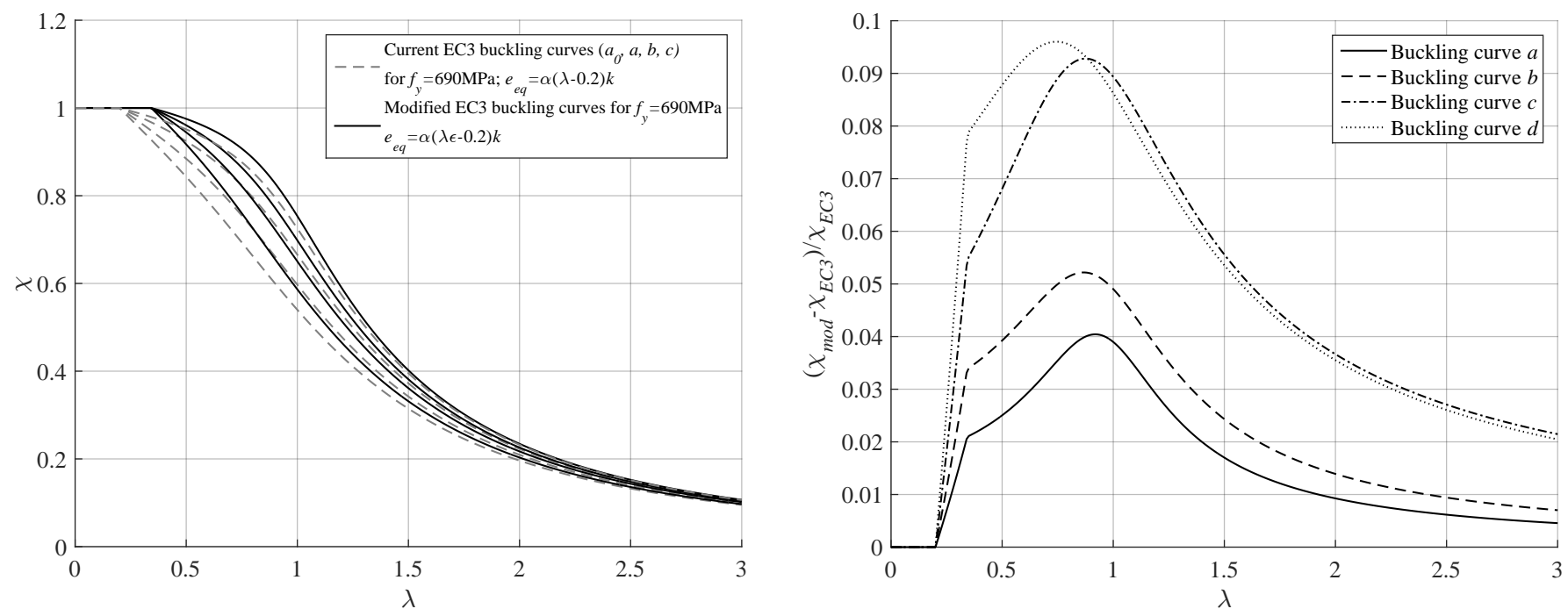

Figure 26: Suggested modified buckling curves for S690 compared to current curves $a_{0}, a, b, c$.
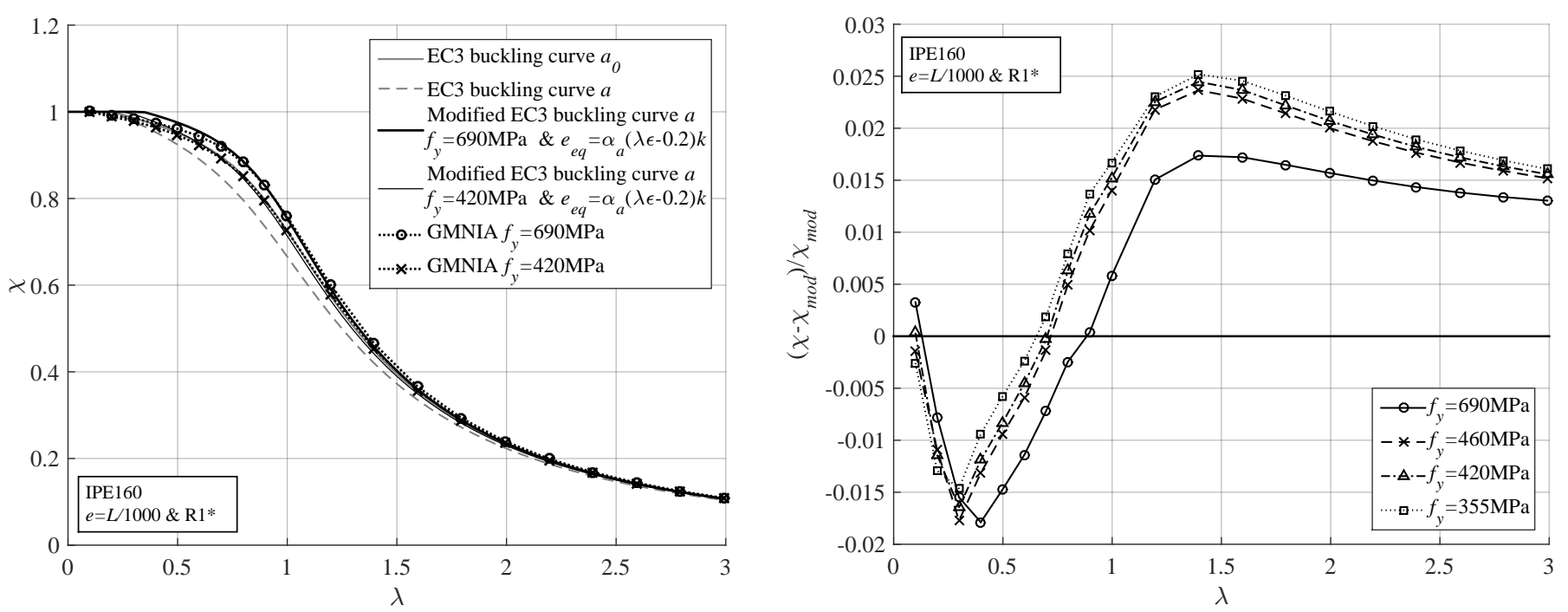

Figure 27: IPE160 with L/1000 bow imperfection and R1* residual stresses compared to modified buckling curve. 

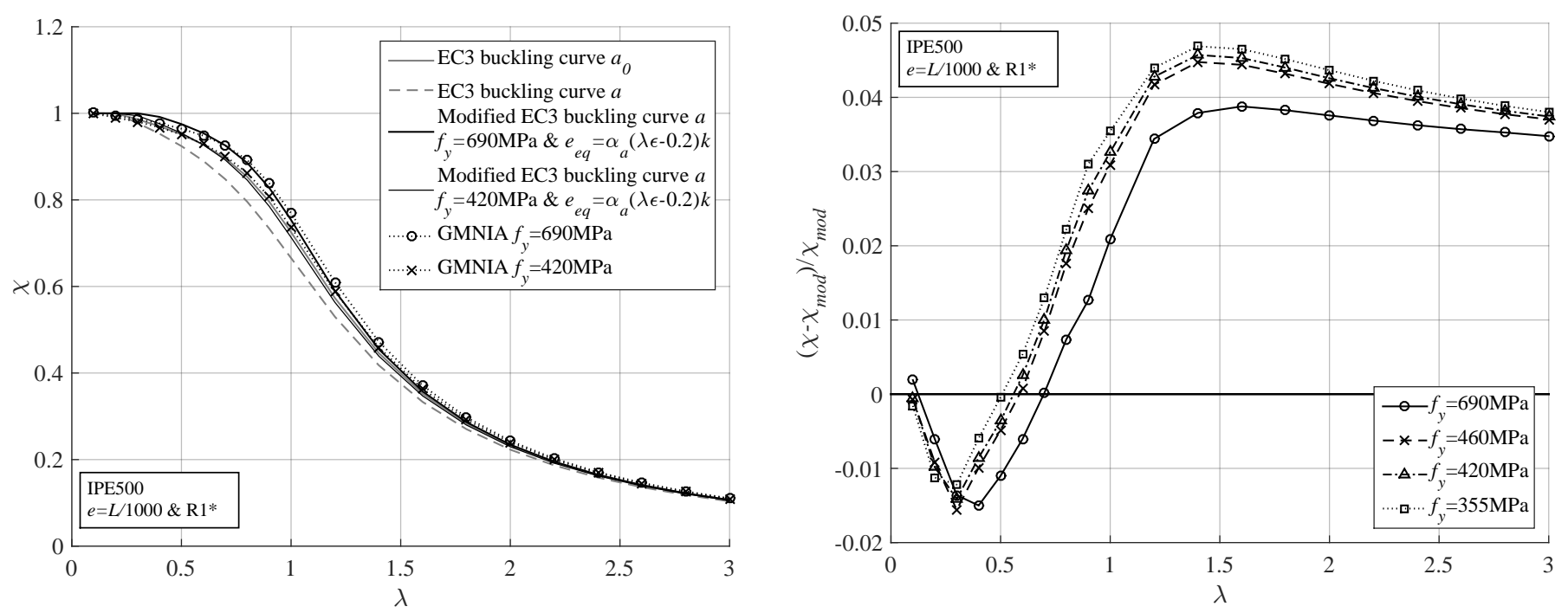

Figure 28: IPE500 with L/1000 bow imperfection and R1* residual stresses compared to modified buckling curve.
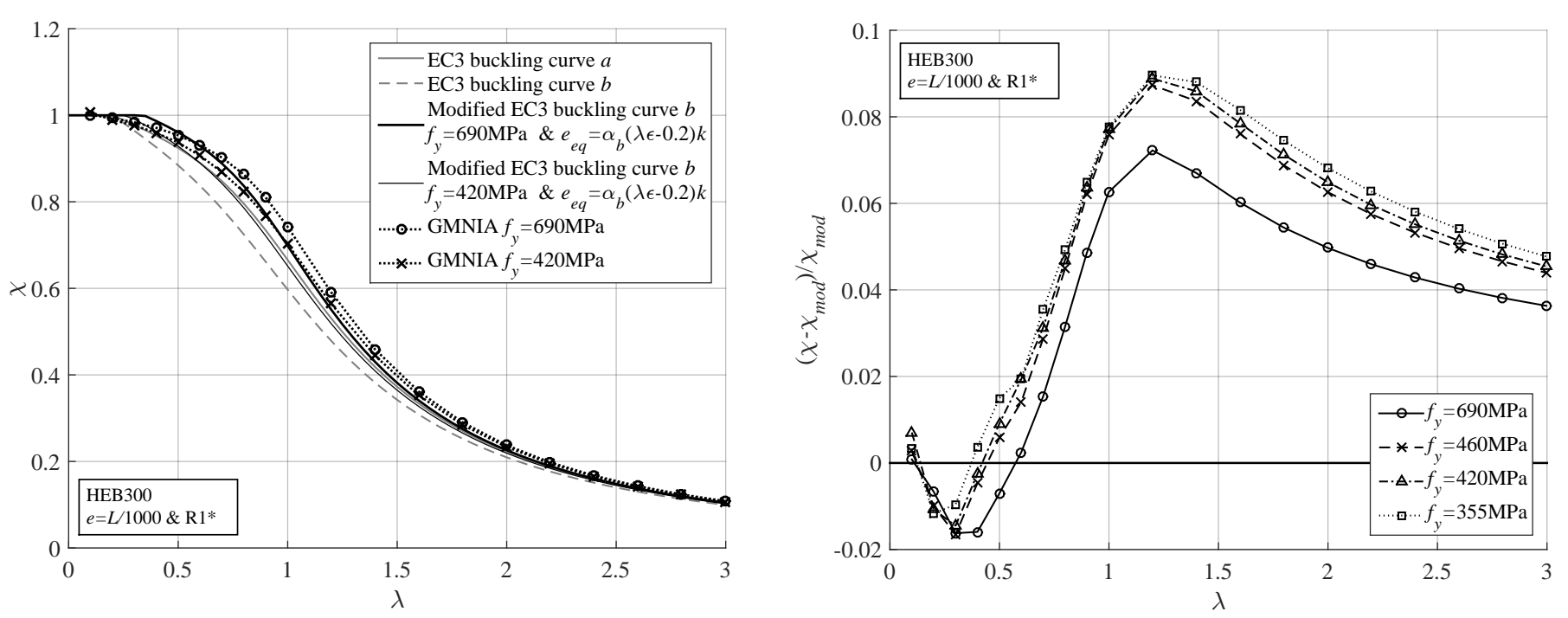

Figure 29: HEB300 with L/1000 bow imperfection and R1* residual stresses compared to modified buckling curve. 


\section{General discussion}

In the present paper finite element results are compared to the EC3 column buckling curves [14] and the discrepancies between the two are shown on separate graphs. This is done since EC 3 buckling curves have been in use for many years and since these curves were used in the calibration of current material safety factors $\gamma_{M}$. However, it should be remembered that based on the work of Maquoi \& Rondal [10] the EC3 buckling curves have been obtained as approximations to the original ECCS buckling curves tabulated in [7]. However, the discrepancy between the original tabulated ECCS buckling curves and the EC 3 buckling curves is relatively small, although as shown by Taras \& Greiner [35] the deviation increases slightly for relative slenderness values greater than one. Thus EC3 becomes more conservative for high slenderness values. Figure 30 shows the original ECCS and the EC3 buckling curves on the left hand side and the discrepancy can be seen on the right hand side. It can be seen that in the low slenderness range the ECCS curves fall slightly below the EC3 curves and that in the high slenderness range the ECCS curves tend to fall above the EC 3 buckling curves (except for buckling curve $b$ ). This behaviour is also reflected in the finite element results, see for example Figures 8 and 9. The ECCS and EC3 buckling curves were derived in the period from 1960 to 1980 and it should be noted that they may not reflect the strength of steel columns produced today by high-end product manufactures. These manufactures may generally have smaller dimensional variability, less geometric imperfections and potentially lower residual stresses, due to improved fabrication methods.

It should be acknowledged that the investigations presented in this paper are limited to rolled I-sections and strong axis flexural buckling. Column strength is shape dependent and relevant buckling curves have to be checked for other cross-section shapes. Therefore even though a new formulation of appropriate column buckling curves has been proposed for I-sections, it has to be investigated whether this formulation also holds for other cross section shapes.

The modified imperfection formulation and thus the introduction of new buckling curves for the Eurocode has to be accompanied by a reliability analysis that derives the material safety factor $\gamma_{M}$. A comprehensive approach would involve gathering of up to date statistical data for geometric imperfections, residual stress distributions and magnitudes, and yield stress from contemporary steel products. This should be followed by Monte Carlo type finite element simulations and use of the Eurocode safety framework to calibrate safety factors. Well aware of these implications, a proposal for a modified formulation has been given in this paper. 

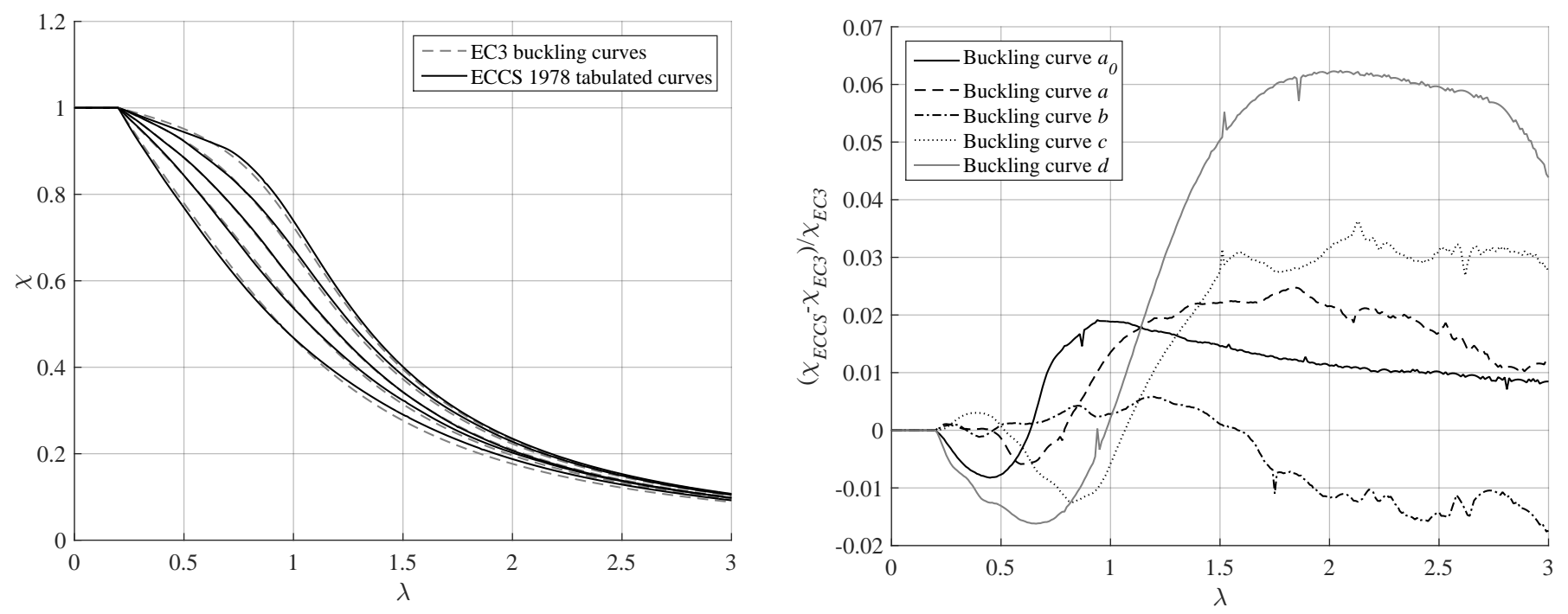

Figure 30: Original ECCS buckling curves compared to EC3 buckling curves.

\section{Conclusion}

It has been shown that it is possible to reestablish the European buckling curves using deterministic non-linear finite element modelling of flexural column buckling using plane shell elements. A short comprehensive historical review of the development of the European buckling curves has been given and related to deterministic modelling.

A large amount of columns have been analysed by advanced geometric and material non-linear analysis with imperfections (GMNIA) using different magnitudes of characteristic yield stress, material stress-strain relationships, and equivalent imperfections and/or residual stresses for standard hot rolled profiles. It is concluded that the linear residual stress distribution can be used to predict accurate results and that its is slightly more conservative compared to the use of the parabolic residual stress distribution. Furthermore, the residual stresses do not seem to scale with the yield stress and should be calculated based on S235 grade steel.

The magnitude of imperfections and residual stresses have been discussed as well as how the use of equivalent imperfections may be very conservative if considered as column imperfections in finite element or frame analysis as described in the current Eurocode code. It is also suggested that finite element or frame analysis may be performed with equivalent column bow imperfections extracted directly from the Ayrton-Perry formulation. Furthermore, a suggestion is given for a slightly modified imperfection formula within the Ayrton-Perry formulation leading to adequate inclusion of modern high grade steels within four yield stress dependent bucking curves using the same buckling parameters $\alpha$ as the Eurocode 3 .

\section{References}

[1] Sfintesco D. Fondement expérimental des courbes européennes de flambement, Construction Métallique, No. 3, 5-12, Sept 1970.
[2] Beer H, Schulz G. Bases théoriques des courbes européenes de flambement, Construction Métallique, No. 3, 37-57, Sept 1970.

[3] Bjorhovde R. Deterministic and probabilistic approaches to the strength of steel columns, PhD Thesis, Lehigh University, Bethlehem, Pa., May 1972.

[4] Strating J, Vos H. Computer simulation of the ECCS buckling curve using a Monte-Carlo Method. HERON, vol. 19, No. 2, 1973.

[5] Dwight JB. Use of Perry formula to represent the new european strut curves, IABSE reports of the working commissions $=$ Rapports des commissions de travail AIPC $=$ IVBH Berichte der Arbeitskommissionen Vol. 23, 1975, http://dx.doi.org/10.5169/seals-19829

[6] ECCS 1976, Manual on Stability of Steel Structures, ECCS Technical Committee 8 - Structural Stability, European Convention for Constructional Steelwork, ECCS-Publication No.22, 2nd. ed., 1976.

[7] ECCS 1978, European recommendations for steel construction, European Convention for Constructional Steelwork, ECCS-Publication No.23, 2nd. ed., 1978.

[8] Ayrton WE, Perry J. On Struts The Engineer, vol. 62, p. 464, 1886.

[9] Robertson A, The Strength of Struts, Institution of Civil Engineers- Selected engineering papers, No. 28, 1-55, London 1925.

[10] Maquoi R, Rondal J. Mise enequation des nouvelles courbe Européennes de flambement, Construction Métallique, No 1, 1978.

[11] Dowling PJ, Finzi L, Janss J, Pousset AG, Sedlacek G, Stark JWB, Hobbs RE. Eurocode No. 3: Common Unified Rules for Steel Structures, Report EUR 8849 DE EN FR, Commission of the European Communities, 1984.

[12] ECCS 1984, Ultimate Limit State Calculation of Sway Frames with Rigid Joints, ECCS Technical Committee 8 - Structural Stability: Technical Working Group 8.2 - System, European Convention for Constructional Steelwork, ECCS-Publication No.33, 1984.

[13] ENV 1993-1-1:1992. Eurocode 3: Design of steel structures - Part 1.1: General rules and rules for buildings, CEN - European committee for Standardization, Brussels (Belgium), 1992.

[14] EN 1993-1-1:2005. Eurocode 3: Design of steel structures - Part 1.1: General rules and rules for buildings, CEN - European committee for Standardization, Brussels (Belgium), 2005.

[15] ECCS 2006, Rules for Member Stability in EN 1993-1-1. Background documentation and design guidelines, European Convention for Constructional Steelwork, ECCS-Publication No.119, 2006.

[16] EN 1993-1-5:2006. Eurocode 3: Design of steel structures - Part 1.5: Plated structural elements, CEN - European committee for Standardization, Brussels (Belgium), 2006.

[17] Johansson B, Maquoi R, Sedlacek, Müller C, Beg D. Commentary and worked examples to EN 1993-1-5 "Plated structural elements", Report EUR 22898, European Commission - Joint Research Centre, Luxembourg, European Communities, 2007.

[18] Alpsten GA. Variations in Mechanical and Cross-Sectional Properties of 
Steel, SBI, Swedish Institute of Steel Construction, Publication No. 42, Sweden, 1973.

[19] Lee CH, Han KH, Uang CM, Kim DK, Park CH, Kim JH. Flexural strength and rotation capacity of I-shaped beams fabricated from 800MPa steel, Journal of Structural Engineering, ASCE, 1043-1058, June 2013.

[20] Boissonade N, Somja H. Influence of imperfections in FEM Modeling of Lateral Torsional Buckling, Proceedings of the Annual Stability confenence, SSRC - Structural Stability Research Council, Grapevine, Texas, April 18-21, 2012.

[21] ABAQUS CAE, v6.13-4, Simulia, 2014.

[22] Kaim P. Spatial buckling behaviour of steel members under bending and compression, $\mathrm{PhD}$ Thesis, Graz University of Technology, Austria, 2004.

[23] EN 1090-2:2008 Execution of steel structures and aluminium structures - Part 2: Technical requirements for steel structures, CEN - European committee for Standardization, Brussels (Belgium), 2008.

[24] Bijlaard F, Feldmann M, Naumes J, Müller C, Sedlacek G. Consistency of equivalent geometric imperfections used in design and the tolerances for geometric imperfections used in execution, Report CEN/TC250CEN/TC135-Liaison, N1721, February 2010.

[25] Greiner R, Kettler Ms, Lechner A, Freytag B, Linder J, Jaspart J-P, Boissonnade N, Bortolotti E, Weynand K, Ziller C, Oerder R. SEMI-COMP: Plastic member capacity of semi-compact steel sections - a more economic design, European Commission, Research Fund for Coal and Steel, Luxembourg: Office for Official Publications of the European Communities. 2009, doi: $10.2777 / 54746$

[26] Ballio G, Mazzolani FM. Theory and design of steel structures, English version, Chapman and Hall, London, New York, 1983.

[27] Shayan S, Rasmussen KJR, Zhang H. Probabilistic modelling of residual stress in advanced analysis of steel structures, Journal of Constructional Steel Research, 101, 407-414, 2014.

[28] Young BW. Residual stresses in hot rolled members, IABSE reports of the working commissions $=$ Rapports des commissions de travail $A I P C=$ IVBH Berichte der Arbeitskommissionen Vol. 23, 1975.

[29] Szalai J, Papp F. A new residual stress distribution for hot-rolled I-shaped sections, Journal of Constructional Steel Research, 61, 845-861, 2005.

[30] Szalai J, Papp F. On the probabilistic evaulation of the stability resistance of steel columns and beams, Journal of Constructional Steel Research, 65, 569-577, 2009.

[31] Kala Z, Kala J. Sensitivity analysis of lateral buckling stability problems of hot-rolled steel beams, Slovak Journal of Civil Engineering, 2, 9-14, 2009.

[32] DNV, Determination of structural capacity by non-linear FE analysis Methods, Recommended Practice, Det Norske Veritas AS, Report DNVRP-C208, June 2013.

[33] Ofner R. Traglasten von Stäbe aus Stahl bei Druck und Biegung, PhDThesis, Technical university of Graz, Heft 9, 1997.

[34] EN 1993-1-12:2007. Eurocode 3: Design of steel structures - Part 1.12: Additional rules for the extension of EN 1993 up to steel grades $S 700$, CEN - European committee for Standardization, Brussels (Belgium), 2007.

[35] Taras A, Greiner R. New design curves for lateral-torsional buckling Proposal based on a consistent derivation, Journal of Constructional Steel Research, 66, 648-663, 2010.

[36] Maquoi R. Some improvements to the buckling design of centrally loaded columns, Structural Stability Research Council, Proceedings of the Annual Meeting, 1982.

[37] Collin P, Johansson B. Eurocode for high strenth steel and applications in construction, Proceedings of Super-High Strength Steels: 1st international conference, Rome, Associazione Italiana di Metallurgia, 2005. 